\title{
Production and destruction of eddy kinetic energy in forced submesoscale eddy-resolving simulations
}

\author{
Sonaljit Mukherjee ${ }^{a, *}$, Sanjiv Ramachandran ${ }^{\mathrm{b}}$, Amit Tandon ${ }^{\mathrm{b}}$, \\ Amala Mahadevan ${ }^{\mathrm{c}}$ \\ ${ }^{a}$ School of Marine Science, University of Massachusetts Dartmouth, 706 S Rodney \\ French Blvd, New Bedford, MA 02744, USA \\ ${ }^{b}$ Dept. of Mechanical Engineering, University of Massachusetts Dartmouth, 285 Old \\ Westport Rd, Dartmouth, MA 02747, USA \\ ${ }^{c}$ Dept. of Physical Oceanography, Woods Hole Oceanographic Institution, 266 Woods \\ Hole Rd, Woods Hole, MA 02543, USA
}

\begin{abstract}
We study the production and dissipation of the eddy kinetic energy (EKE) in a submesoscale eddy field forced with downfront winds using the Process Study Ocean Model (PSOM) with a horizontal grid resolution of $0.5 \mathrm{~km}$. We simulate an idealized $100 \mathrm{~m}$ deep mixed-layer front initially in geostrophic balance with a jet in a domain that permits eddies within a range of $\mathrm{O}(1$ $\mathrm{km}-100 \mathrm{~km})$. The vertical eddy viscosities and the dissipation are parameterized using four different subgrid vertical mixing parameterizations: the $k-\epsilon$, the KPP, and two different constant eddy viscosity and diffusivity profiles with a magnitude of $\mathrm{O}\left(10^{-2} \mathrm{~m}^{2} \mathrm{~s}^{-1}\right)$ in the mixed layer. Our study shows that strong vertical eddy viscosities near the surface reduce the parameterized dissipation, whereas strong vertical eddy diffusivities reduce the lateral buoyancy gradients and consequently the rate of restratification by mixed-layer instabilities (MLI).

Our simulations show that near the surface, the spatial variability of the dissipation along the periphery of the eddies depends on the relative
\end{abstract}

*Principal corresponding author. Address: School of Marine Science, University of Massachusetts Dartmouth, 706 S Rodney French Blvd, New Bedford, MA 02744. Tel: $+1-508-542-8422$

Email addresses: smukherjee@umassd.edu (Sonaljit Mukherjee), sramachandran@umassd.edu (Sanjiv Ramachandran), atandon@umassd.edu (Amit Tandon ), amala@whoi.edu (Amala Mahadevan ) 
alignment of the ageostrophic and geostrophic shear. Analysis of the resolved EKE budgets in the frontal region from the simulations show important similarities between the vertical structure of the EKE budget produced by the $k-\epsilon$ and KPP parameterizations, and earlier LES studies. Such an agreement is absent in the simulations using constant eddy-viscosity parameterizations.

Keywords:

Submesoscale, Mixed layer, Dissipation, Eddies, Restratification, Vertical mixing

\section{Introduction}

Fronts in the upper ocean are prone to mixed-layer instabilities (MLI) that spawn $\mathrm{O}(1-10 \mathrm{~km})$ submesoscale eddies (Boccaletti et al., 2007). These eddies are characterized by $\mathrm{O}(1)$ Rossby numbers and $\mathrm{O}(1)$ Richardson num5 bers, implying a departure from quasi-geostrophic dynamics (Charney, 1971; Stone, 1966, 1970). The MLI extracts available potential energy (APE) associated with the lateral density gradients and converts it to Eddy Kinetic Energy (EKE) forming ageostrophic circulations that restratify the mixed layer by slumping of the isopycnals (Boccaletti et al., 2007; Capet et al., 2008a,b; Fox-Kemper et al., 2008; Fox-Kemper and Ferrari, 2008; Klein et al., 2008; Mahadevan, 2006; Mahadevan and Tandon, 2006; Thomas et al., 2008). The increase in stratification by the MLI over a few days can be as high as an order of magnitude larger than that achieved by geostrophic adjustment alone (Boccaletti et al., 2007; Tandon and Garrett, 1994b,a).

15 Recent studies have shown several processes across a wide spectrum of scales $\mathrm{O}(1 \mathrm{~m}-10 \mathrm{~km})$ to be active at mixed-layer fronts. These processes include ageostrophic baroclinic instabilities (ABI) (Boccaletti et al., 2007; Stone, 1966, 1970), symmetric instability (SI) (D'Asaro et al., 2011; Nagai et al., 2012; Taylor and Ferrari, 2009, 2010, 2011; Thomas and Taylor, 2010; Thomas et al., 2013) and other types of MLI (Molemaker et al., 2005).

$\mathrm{ABI}$ and SI extract the available potential energy (APE) associated with the lateral buoyancy gradients and convert it to EKE (Bachman and Taylor, 2014; D'Asaro et al., 2011; Taylor and Ferrari, 2010; Thomas and Taylor, 2010; Thomas et al., 2013) which is cascaded to smaller scales. SI also extracts the geostrophic kinetic energy associated with lateral density gradients and cascades it to smaller scales by secondary shear instabilities (Taylor and Ferrari, 2009). Observations show that the forward cascade of EKE initiated 
by SI leads to enhanced dissipation at density fronts (D'Asaro et al., 2011; Thomas et al., 2013). Smaller scale processes include turbulence driven by winds, convection and surface waves (Grant and Belcher, 2009; Hamlington et al., 2014; Haney et al., 2015). Due to computational limits, it is prohibitive to resolve these $\mathrm{O}(1 \mathrm{~m}-10 \mathrm{~km})$ processes simultaneously in one simulation, although there have been studies using Large Eddy Simulations (LES) that resolve both 3-dimensional (3D) turbulence and submesoscale motions (Hamlington et al., 2014; Haney et al., 2015). For non-LES studies that focus on the evolution of $\mathrm{O}(1-10 \mathrm{~km})$ eddies, it is necessary to parameterize the mixing associated with these smaller-scale processes.

Numerical simulations of mixed-layer fronts have shown that the submesoscale eddy field is subject to active frontogenesis near the surface and exhibits $\mathrm{O}(f)$ vertical relative vorticities ( $f$ is the Coriolis frequency) and $\mathrm{O}(100$ $\mathrm{m} /$ day) vertical velocities within the mixed layer (Capet et al., 2008a,b; Lapeyre et al., 2006; Mahadevan and Tandon, 2006; Shakespeare and Taylor, 2013; Thomas, 2008; Thomas et al., 2008). Frontogenesis occurs through the following processes: i) horizontal deformation by a confluent mesoscale flow 45 (Capet et al., 2008b; Hoskins and Bretherton, 1972), ii) ageostrophic crossfrontal circulation driven by downfront winds (Thomas and Lee, 2005), and iii) baroclinic waves that cause submesoscale frontogenesis (Shakespeare and Taylor, 2013).

Non-LES simulations with $\mathrm{O}(1 \mathrm{~km})$ grid resolution have shown that MLI other than SI can convert the APE in the lateral gradients to EKE and cascade it to smaller scales (Capet et al., 2008c). Earlier non-LES submesoscale resolving simulations have used a horizontal grid resolution ranging from 0.5 $\mathrm{km}$ to $1 \mathrm{~km}$ and vertical resolution of $\mathrm{O}(1-10 \mathrm{~m}$ ) (Capet et al., 2008a,b,c; Fox-Kemper et al., 2008; Fox-Kemper and Ferrari, 2008; Fox-Kemper et al., 2013). As these simulations do not resolve 3D turbulence, the dissipation of EKE at the smallest scales in these simulations must be inferred from subgrid-scale parameterizations for vertical mixing (Capet et al., 2008a,b,c; Fox-Kemper et al., 2008, 2011; Fox-Kemper and Ferrari, 2008; Marques and Özgökmen, 2014; Ramachandran et al., 2013).

Parameterizing the mixing in earlier non-LES submesoscale resolving simulations has been done using the following methods: (i) prescribing constant eddy viscosities and eddy diffusivities for vertical and horizontal mixing (FoxKemper et al., 2008), (ii) prescribing a vertically varying eddy viscosity profile that depends on the Ekman-layer depth (Mahadevan, 2006; Mahade- 
van and Tandon, 2006; Mahadevan et al., 2010), (iii) implementing the turbulence closure parameterizations $k-\epsilon$ (Gibson and Launder, 1976; Rodi, 1976), $k-k L$ (Mellor and Yamada, 1982) and the K-profile parameterization (KPP) (Large et al., 1994). The KPP and turbulence closure parameterizations estimate vertical eddy viscosities and diffusivities as functions of the water-column characteristics and surface forcing (Capet et al., 2008a; Marques and Özgökmen, 2014). The $k-\epsilon$ parameterization is composed of two prognostic equations for the subgrid EKE and its dissipation rate $\epsilon$ (Burchard and Bolding, 2001; Gibson and Launder, 1976; Rodi, 1976; Umlauf and Burchard, 2005). The KPP prescribes a vertical eddy viscosity profile using a cubic polynomial shape function within the surface boundary layer whose depth is estimated based on a threshold of the Bulk Richardson number (Large et al., 1994). While the dissipation in the $k-\epsilon$ parameterization is obtained through a separate prognostic equation for $\epsilon$, the inferred dissipation in other parameterizations that provide only the eddy viscosity, such as the KPP, can be approximated from the eddy viscosity and the resolved-scale vertical shear.

The sensitivity of submesoscale-resolving simulations to different subgrid mixing parameterizations has been demonstrated in earlier studies (Marques and Özgökmen, 2014; Ramachandran et al., 2013). These studies have shown that high horizontal and vertical eddy viscosities (and diffusivities) diminish the growth rate of the MLI. Unforced simulations of a mixed-layer front (Marques and Özgökmen, 2014) using the KPP have shown that the KPP produces insufficient vertical mixing during the MLI adjustment in (Ramachandran et al., 2013) have shown that at resolved scales, the EKE budget averaged over the eddy field shows two distinct characteristics: (i) a shear-driven layer near the surface where the ageostrophic shear production and the dissipation of EKE form a leading order balance, and (ii) a buoyancydriven layer below the shear-driven layer where the leading order term is the buoyancy flux associated with the ABI induced restratification. This vertical structure differs from that seen in the LES simulations of a mixed-layer front with surface cooling (Taylor and Ferrari, 2010) where a convective layer with negative PV forms near the surface, overlying a forced SI layer with nearzero PV. Taylor and Ferrari (2010) have further shown that the addition of a wind-induced buoyancy flux further divides the low-PV region near the surface into a shear-driven layer where turbulence is dominated by the wind stress, a convective layer and a forced SI layer. 
Non-LES submesoscale resolving simulations with $\mathrm{O}(1 \mathrm{~km})$ grid resolution do not resolve the entire range of scales spanning the forward cascade of EKE. This implies a flux of EKE from the resolved to the subgrid scales, which is removed by the dissipation inferred from the mixing parameterizations. While the resolved-scale budget of EKE under wind-forced conditions have been analyzed in earlier studies (Capet et al., 2008c; Ramachandran et al., 2013), the vertical structure of the subgrid-scale EKE budget needs to be explored. Unlike the KPP or the parameterizations using constant eddy viscosities, the $k-\epsilon$ enables us to explore in greater detail the mechanisms responsible for the production and destruction of EKE at subgrid scales.

Analyses of the frontally averaged statistics have revealed important differences between the intensity of turbulence near and away from the mixedlayer fronts under different forcing conditions. For instance, observations at the Kuroshio front have shown that the extraction of EKE by SI in the presence of downfront winds leads to enhanced dissipation (D'Asaro et al., 2011; Nagai et al., 2012). Analysis of the wintertime surveys in the Gulf Stream (Thomas et al., 2013) has shown that the extraction of APE by ageostrophic baroclinic instability is equivalent in magnitude to the dissipation of EKE by symmetric instability (Thomas et al., 2013). Dissipation caused by the forward cascade of EKE by ABI has been noted in non-LES simulations (Capet et al., 2008c). At smaller scales, surface waves have been observed to enhance the vertical mixing and turbulent dissipation in the mixed layer, both with and without density fronts (Hamlington et al., 2014; Skyllingstad and Denbo, 1995).

\subsection{Motivation}

Motivated by the discussions above, we aim to explore the following questions in this study:

- How do the properties of the resolved submesoscale eddy field vary with different subgrid mixing parameterizations?

- How does the dissipation of EKE vary spatially within a forced submesoscale eddy field generated by a mixed-layer front? What are the underlying causes for its spatial variation?

- What is the vertical structure of the subgrid EKE budget in a forced submesoscale eddy field, and what are the leading order contributors? 
In this paper, we conduct submesoscale-resolving simulations of a mixedlayer front forced with downfront winds. We use the 3D Process Study Ocean Model (PSOM) (Mahadevan, 2006) with the following vertical mixing parameterizations: the Ekman-layer based parameterization (Mahadevan et al., 2010), the $\mathrm{k}-\epsilon$ (Rodi, 1976) and the KPP (Large et al., 1994) for estimating the eddy viscosities and diffusivities.

The remaining of the paper is outlined as follows: Section 2 describes the numerical model PSOM and the mixing parameterizations in detail. Section 3 describes the initial condition (3.1), the surface forcing (3.2) and the simulations (3.3). Section 4 shows the results that include analysis of the instantaneous eddy fields (4.1), contrasts between the different simulations (4.2), the spatial variability of the parameterized dissipation with the flow properties (4.3), the variability of dissipation based on the frontal orientation (4.4) and the EKE budget at resolved and subgrid scales (4.5). Section 5 presents the conclusions of our process studies.

\section{Numerical model}

PSOM (Mahadevan, 2006) is a three dimensional model that uses Boussinesq equations numerically discretized using the Quadratic Upstream Interpolation for Convective Kinematics (QUICK) scheme (Leonard, 1988). We use this model in a zonally periodic re-entrant domain, which implies periodic boundary conditions on the West and East boundaries and wall boundary conditions along the South and North boundaries. The top-grid face is the 160 height of the free surface. The next section sets out the model equations for the momentum and scalar transport.

\subsection{Model Equations}

The model equations for the temperature, salinity and velocities are given below (Mahadevan, 2006). The resolved-scale quantities are denoted with an overline.

$$
\begin{gathered}
D_{t} \bar{T}=-\frac{\partial}{\partial x_{j}} F_{j}^{R}-\frac{\partial}{\partial x_{j}} \tau_{j}^{T}, \\
D_{t} \bar{S}=-\frac{\partial}{\partial x_{j}} \tau_{j}^{S},
\end{gathered}
$$




$$
\begin{gathered}
D_{t} \bar{u}+\operatorname{Ro}^{-1}\left(\bar{p}_{x}+\lambda \bar{q}_{x}-f \bar{v}+\operatorname{Ro} \delta b \bar{w}\right) \\
=-\frac{\partial}{\partial x_{j}} \tau_{i j} ; \quad i=1 \\
D_{t} \bar{v}+\operatorname{Ro}^{-1}\left(\bar{p}_{y}+\lambda \bar{q}_{y}+f \bar{u}\right) \\
=-\frac{\partial}{\partial x_{j}} \tau_{i j} ; i=2 \\
D_{t} \bar{w}+\operatorname{Ro}^{-2} \delta^{-1}\left(\frac{\lambda}{\delta} \bar{q}_{z}-b \bar{u}\right)=-\frac{\partial}{\partial x_{j}} \tau_{i j} ; i=3 \\
\bar{u}_{x}+\bar{v}_{y}+\operatorname{Ro} \bar{w}_{z}=0,
\end{gathered}
$$

where $D_{t}$ denotes the non-dimensional material derivative expressed as $\partial t+$ $\bar{u} \partial_{x}+\bar{v} \partial_{y}+\operatorname{Ro} \bar{w} \partial z$. The variables $\bar{T}, \bar{S} \bar{u}, \bar{v}$ and $\bar{w}$ are the resolved components of temperature, salinity and the non-dimensional velocities along the $x$ (zonal), $y$ (meridional) and $z$ (vertical) coordinates respectively. The variables $\bar{p}$ and $\bar{q}$ are the resolved non-dimensional hydrostatic and nonhydrostatic components of pressure respectively. The variable $\lambda$ denotes the ratio of the variations of $\bar{q}$ and $\bar{p}$. The hydrostatic-pressure component $\bar{p}$ satisfies $\frac{\partial}{\partial z} \bar{p}+\bar{\rho} g=0$ where $g$ is the acceleration due to gravity. The model can be used in both hydrostatic or non-hydrostatic mode by setting $\lambda$ to either 0 or the aspect ratio $\delta$. The variables $F_{j}^{R}, \tau_{j}^{T}, \tau_{j}^{S}$ and $\tau_{i j}$ on the right hand side are non-dimensional and denote the penetrative solar heat flux, the subgrid flux for temperature, salinity and momentum respectively.

The relevant scaling parameters for the distances are the horizontal and vertical length-scales $L$ and $D$. Scaling parameters for the velocities are the horizontal and vertical velocity scales $U$ and $W$ respectively. The variables $\delta=D / L$ and $\operatorname{Ro}=U /(2 \Omega L)$ are the aspect ratio and the Rossby number respectively, where $\Omega$ is the angular velocity of the Earth's rotation. In the equations $1 \mathrm{c}-1 \mathrm{e}$, the components of the Coriolis acceleration, non-dimensionalized with $\Omega$, are $f=2 \sin (\theta)$ and $b=2 \cos (\theta)$ where $\theta$ is the latitude.

Since the magnitudes of the subgrid-scale flux divergence are not known, a parameterization is necessary in order to address the flux-divergence terms 
and close the model equations to numerically solve for the resolved quantities. The stress divergence terms in the equations 1a-1e are parameterized as

$$
\begin{gathered}
-\frac{\partial}{\partial x_{j}} \tau_{j}^{T}=(U L)^{-1} \frac{\partial}{\partial x_{j}}\left(k_{h s} \frac{\partial}{\partial x_{j}} \bar{T}\right)_{j=1,2} \\
+(U L)^{-1} \delta^{-2} \frac{\partial}{\partial x_{j}}\left(\nu_{s} \frac{\partial}{\partial x_{j}} \bar{T}\right)_{j=3}, \\
-\frac{\partial}{\partial x_{j}} \tau_{j}^{S}=(U L)^{-1} \frac{\partial}{\partial x_{j}}\left(k_{h s} \frac{\partial}{\partial x_{j}} \bar{S}\right)_{j=1,2} \\
+(U L)^{-1} \delta^{-2} \frac{\partial}{\partial x_{j}}\left(\nu_{s} \frac{\partial}{\partial x_{j}} \bar{S}\right)_{j=3}, \\
-\frac{\partial}{\partial x_{j}} \tau_{i j}=(U L)^{-1} \frac{\partial}{\partial x_{j}}\left(k_{h} \frac{\partial}{\partial x_{j}} \overline{u_{i}}\right)_{j=1,2} \\
+(U L)^{-1} \delta^{-2} \frac{\partial}{\partial x_{j}}\left(\nu_{m} \frac{\partial}{\partial x_{j}} \overline{u_{i}}\right)_{j=3},
\end{gathered}
$$

where $k_{h}$ and $k_{h s}$ are the horizontal eddy viscosities and eddy diffusivities in dimensional form respectively. The variables $\nu_{m}$ and $\nu_{s}$ are the vertical eddy viscosities and eddy diffusivities respectively.

In submesoscale-resolving simulations, lateral density gradients which are reservoirs of APE, get diffused by the prescribed horizontal eddy diffusivities. In our studies, since we intend to explore the influence of only the vertical mixing parameterizations on the resolved flow field, we prescribe zero horizontal eddy viscosities and diffusivities ${ }^{1}$ in our simulations. The vertical eddy viscosities and diffusivities are obtained using the following mixing parameterizations discussed below.

\subsection{Vertical mixing parameterizations}

To estimate the eddy viscosities, we choose three different vertical mixing schemes: (i) a parameterization based on the Ekman-layer depth (Ekman,

\footnotetext{
${ }^{1}$ Mohammadi-Aragh et al. (2015) show the influence of numerical dissipation in advection schemes on the restratification. The horizontal implicit numerical diffusivity for a canonical frontal jet, obtained from our simulations, is $10^{-3} \mathrm{~m}^{2} \mathrm{~s}^{-1}$ as tested by dispersion of a passive tracer in an unforced simulation.
} 
1905; Mahadevan et al., 2010); (ii) the $k-\epsilon$ model (Rodi, 1976) and (iii) the K profile parameterization (KPP) (Large et al., 1994).

\subsubsection{Parameterization based on the Ekman-layer depth}

Here, the eddy viscosities (and diffusivities) are estimated explicitly as a hyperbolic tangent function of the depth $(z)$ and the Ekman-layer depth $\left(D_{e k}\right)$ (Ekman, 1905; Mahadevan et al., 2010) as

$$
\begin{aligned}
& D_{e k}=0.4 \frac{u_{*}}{f} \\
& \nu_{m}=\nu_{s}= \\
& \max \left(\nu_{\max }\left[\frac{1}{2}\left(1+\tanh \left(\frac{z-\gamma_{1} D_{e k}}{\gamma_{2} D_{e k}}\right)\right)\right], 10^{-5}\right),
\end{aligned}
$$

where $u_{*}=\sqrt{\tau} / \rho_{0}$ and $\nu_{\max }$ are the dimensional friction velocity and maximum eddy viscosity within the Ekman layer respectively. We modify the diffusivity expression used by Mahadevan et al. (2010) by adding the variables $\gamma_{1}$ and $\gamma_{2}$ in order to adjust the shape of the diffusivity profile such that it transitions smoothly from a background value of $10^{-5} \mathrm{~m}^{2} \mathrm{~s}^{-1}$ in the interior to the maximum value $\nu_{\max }$ (table 2) within the Ekman layer.

\subsection{2. $k-\epsilon$ parameterization}

The $k-\epsilon$ is a one-dimensional mixing model that evolves the turbulent kinetic energy $k$ and its rate of dissipation $(\epsilon)$ (Rodi, 1976). The parameterized equation for $k$ is

$$
\begin{gathered}
\frac{D}{D t} k=\underbrace{\frac{\partial}{\partial z}\left(\frac{\nu_{m}}{\sigma_{k}} \frac{\partial}{\partial z} k\right)}_{\text {Downgradient transfer } \mathrm{D}_{\mathrm{k}}}+\underbrace{\nu_{m} S^{2}}_{\text {Shear production } \mathrm{P}} \\
\underbrace{-\nu_{s} N^{2}}_{\text {Buoyancy production B }}-\underbrace{\epsilon}_{\text {Dissipation }},
\end{gathered}
$$

where $\frac{D}{D t}$ is the (dimensional) material derivative and $\sigma_{k}=1$ is the Schmidt number (Burchard and Bolding, 2001) for $k$. The shear production term $P$ and buoyancy production term $B$ are parameterized as $P=\nu_{m} S^{2}$ and $B=-\nu_{s} N^{2}$ where $S$ and $N^{2}$ are the vertical shear and the Brunt-Väisälä frequency respectively. The term $D_{k}$ is a downgradient parameterization for 
the triple-order turbulent transport terms in the $k$ budget (Burchard et al., 1999; Rodi, 1976). The variable $\epsilon$ represents the removal of $k$ at the smallest scale by viscous destruction.

The evolution of $\epsilon$ is parameterized by the following equation (Rodi, 1976):

$$
\left.\frac{D}{D t} \epsilon=\underset{\substack{\partial z \\ \text { Downgradient transfer } \mathrm{D}_{\epsilon}}}{\frac{\partial}{\sigma_{e}}} \frac{\partial \epsilon}{\partial z}\right) \epsilon / k\left(c_{e 1} P+c_{e 3} B-c_{e 2} \epsilon\right),
$$

where $D_{\epsilon}$ is a downgradient parameterization analogous to the one in equation 4 and $\sigma_{e}=1.3$ is the Schmidt number for $\epsilon$ (Burchard and Bolding, 2001). The remaining terms on the right represent the sources and sinks of $\epsilon$. The parameters $c_{e 1}, c_{e 2}$ and $c_{e 3}$ are empirically determined coefficients (Rodi, 1976). The coefficients $c_{e 1}$ and $c_{e 2}$ are set to 1.44 and 1.92 respectively, whereas $c_{e 3}$ varies between -0.62 and 1.0 for stable and unstable stratification respectively (Burchard et al., 1999).

The eddy viscosities and eddy diffusivities are estimated as functions of $k$ and $\epsilon$ as

$$
\begin{aligned}
\nu_{m} & =c_{\mu} \frac{k^{2}}{\epsilon}, \\
\nu_{s} & =c_{\mu}^{\prime} \frac{k^{2}}{\epsilon} .
\end{aligned}
$$

The variables $c_{\mu}$ and $c_{\mu}^{\prime}$ are empirically derived non-dimensional functions of the shear number $\alpha_{M}=\left(k^{2} / \epsilon^{2}\right) S^{2}$ and buoyancy number $\alpha_{N}=\left(k^{2} / \epsilon^{2}\right) N^{2}$ (Rodi, 1976). Following the closure assumptions of Canuto et al. (2001), the stability functions are expressed as

$$
\begin{aligned}
& c_{\mu}=\frac{0.1070+0.01741 \alpha_{N}-0.00012 \alpha_{M}}{A}, \\
& c_{\mu}^{\prime}=\frac{0.1120+0.004519 \alpha_{N}+0.00088 \alpha_{M}}{A},
\end{aligned}
$$

where $A=1+0.26 \alpha_{N}+0.029 \alpha_{M}+0.0087 \alpha_{N}^{2}+0.005 \alpha_{N} \alpha_{M}-0.000034 \alpha_{M}^{2}$.

\subsubsection{K-Profile Parameterization (KPP)}

This parameterization calculates a surface boundary-layer depth $z_{b l}$ based on a threshold magnitude of the Bulk Richardson number, and estimates the eddy viscosity $\nu_{m}$ as

$$
\nu_{m}=z_{b l} w_{s} H(\sigma)
$$


where

$$
\begin{aligned}
H(\sigma) & =\sigma[1+\sigma((\sigma-2) \\
& \left.\left.+(3-2 \sigma) H(1)+(\sigma-1) H^{\prime}(1)\right)\right]
\end{aligned}
$$

is a dimensionless cubic shape function of the non-dimensional depth $\sigma=$ $z / z_{b l}$. The variable $w_{s}$ is the turbulent velocity scale for momentum and buoyancy, given as

$$
w_{s}=\frac{\kappa u_{*}}{\Phi(\xi)}
$$

where $\kappa$ is the Von Kármán constant of 0.4 , and $\Phi$ is a non-dimensional function of a stability parameter $\xi$ which varies based on the stability of the boundary-layer forcing (Durski et al., 2004; Large et al., 1994). When there is no surface buoyancy flux, $\Phi=1$.

Apart from mixing within the boundary layer, the KPP implements simplistic schemes for interior mixing associated with shear-driven turbulence, double diffusion and internal waves (Large et al., 1994) below the boundary layer. The eddy viscosity corresponding to shear-driven mixing is parameterized as

$$
\nu_{s h}= \begin{cases}\nu_{0} & R i_{g}<0, \\ \nu_{0}\left[1-\left(R i_{g} / 0.7\right)^{2}\right]^{3}, & 0<R i_{g}<0.7 \\ 0 & R i_{g}>0.7\end{cases}
$$

where $\nu_{0}=5 \times 10^{-3} \mathrm{~m}^{2} \mathrm{~s}^{-1}$ and $R i_{g}=N^{2} / S^{2}$ is the gradient Richardson number at the base of the boundary layer. The mixing corresponding to double diffusion and internal waves is turned off in our simulations.

\subsection{General Ocean Turbulence Model}

The General Ocean Turbulence Model (GOTM) is a 1D model framework that contains a suite of vertical mixing parameterizations for the $1 \mathrm{D}$ water column including the $k-\epsilon$ and the KPP (Burchard et al., 1999). GOTM can be used either in a standalone mode where it solves the 1D momentum and scalar transport equations, or in the form of a module that can be accessed by $3 \mathrm{D}$ ocean models for estimating the eddy viscosities. We modify the $k-\epsilon$ parameterization embedded in the GOTM by including the resolved advection of $k$ and $\epsilon$ by the horizontal velocities obtained from PSOM. In our simulations, GOTM is used as a module accessed by PSOM to estimate the mixing coefficients at each time step, as outlined below. 
- At every time step PSOM provides the stratification $N^{2}(z)$, shear squared $S^{2}(z)$, the cell thickness and surface wind stress at every $(x, y)$ to GOTM.

- Using these inputs, the vertical mixing parameterization in GOTM estimates profiles of eddy viscosities and diffusivities at each $(x, y)$ which are then passed back to PSOM.

- PSOM uses these eddy viscosities and diffusivities to update the momentum and scalar quantities using their prognostic equations.

\section{Model Setup}

250

\subsection{Initial condition}

We initialize the 3D model with an idealized mixed-layer front in thermal wind balance with a frontal jet, a configuration used in earlier submesoscale process studies (Mahadevan, 2006; Mahadevan and Tandon, 2006; Ramachandran et al., 2013). The front is prescribed within the mixed layer as a hyperbolic tangent function of the temperature along the meridional axis as follows:

$$
T(y)=20+0.6\left[1-\tanh \left(\frac{y-L_{y} / 2}{10}\right)\right]
$$

where $L_{y}=192 \mathrm{~km}$ is the meridional extent of the domain. The front is oriented in the zonal direction and is located at a latitude of $32^{\circ} \mathrm{N}$ corresponding to a 22 hour inertial period. The meridional buoyancy gradient is $1.3 \times 10^{-7} \mathrm{~s}^{-2}$ (figure 1), similar to typical values observed in the Atlantic Ocean mixed layer (Mahadevan et al., 2012). We prescribe a spatially varying sea-surface elevation such that the barotropic pressure gradient balances the baroclinic pressure gradient at $100 \mathrm{~m}$ depth. The zonal velocity formed by thermal wind balance is $0.2 \mathrm{~m} / \mathrm{s}$ at the surface. The initialized mixedlayer depth in our simulations is $100 \mathrm{~m}$. We define the mixed-layer depth (MLD) as the depth where the density is $0.03 \mathrm{~kg} / \mathrm{m}^{3}$ larger than the surface density. The vertical stratification within the mixed layer is $1.5 \times 10^{-7} \mathrm{~s}^{-2}$. This initial configuration makes the $\mathrm{PV}$ in the mixed layer negative over a $12 \mathrm{~km}$ wide zonal strip in the frontal region. To nudge the onset of the instabilities, we perturb the initial state by applying a sinusoidal wiggle to the 265 temperature in the frontal region of amplitude $0.005^{0} \mathrm{C}$ and a wavelength equal to the zonal extent (table 1) of the domain. 
The length-scale and time-scale corresponding to the fastest growing mode of non-geostrophic baroclinic instability are given by $L_{s}=\frac{2 \pi U}{|f|} \sqrt{\frac{(1+R i)}{5 / 2}}$ and $t_{s}=\sqrt{\frac{54}{5}} \frac{\sqrt{1+R i}}{|f|}$ (Stone, 1966, 1970) where $U$ is a typical velocity scale of the geostrophic flow. Using a representative jet velocity of $0.1 \mathrm{~m} / \mathrm{s}$ (the mean of the geostrophic velocity over the mixed layer), the mixed-layer $\mathrm{Ri}=0.5$ and Coriolis parameter $f=7.7 \times 10^{-5} \mathrm{~s}^{-1}$, we obtain a length-scale of $7 \mathrm{~km}$ and a time-scale of 16 hours. The horizontal grid resolution in our simulations is $0.5 \mathrm{~km}$. Table 1 presents the different simulation parameters.

\subsection{Surface forcing}

Wind stress is a source of turbulent kinetic energy which results in turbulent mixing of the water column and entrainment of deeper water into the mixed-layer (Kato and Phillips, 1969). For a zonal front with buoyancy reducing from South to North, winds blowing towards the east advect the denser water near the surface towards the lighter water by Ekman advection (Mahadevan et al., 2010). The resulting destratification by this advection counters the restratification due to the MLI (Mahadevan et al., 2010). To assess the relative influence of the wind-driven destratification and the eddydriven restratification, Mahadevan et al. (2010) introduced a parameter $r$, the ratio of $\psi / \psi_{e}$ where $\psi$ is a stream function for the wind-driven circulation and $\psi_{e}$ is a stream function that characterizes the MLI induced circulation (Fox-Kemper et al., 2008, 2011; Fox-Kemper and Ferrari, 2008). The expressions for $\psi, \psi_{e}$ and $\mathrm{r}$ are as follows:

$$
\begin{array}{r}
\psi=-\tau_{0} / \rho_{0} f, \\
\psi_{e}=0.06 H^{2} \nabla B / f, \\
r=\left|\frac{\psi}{\psi_{e}}\right|,
\end{array}
$$

where $\tau_{0}, \rho_{0}, H$ and $\nabla B$ are the wind stress, reference density, mixed-layer depth and frontal buoyancy gradient respectively. When $r \geq 1$, the isopycnal slumping is arrested by the downfront wind and the growth of MLI and restratification is inhibited. When $r<1$, the eddy-driven restratification dominates over the wind-induced destratification (Mahadevan et al., 2010).

We impose a westerly wind stress that varies sinusoidally from the South to North with a maximum magnitude of $0.1 \mathrm{Nm}^{-2}$ at $y=96 \mathrm{~km}$ (figure 1) as follows:

$$
\tau_{x}(y)=\max \left[\left(0.13 \sin \left(\pi y / L_{y}\right)-0.03\right), 0\right] .
$$


The chosen magnitude of $\tau_{x}=0.1 \mathrm{Nm}^{-2}$ at $y=96 \mathrm{~km}$ corresponds to $r \sim 1$. The resulting wind stress tapers to $0 \mathrm{~N} / \mathrm{m}^{2}$ at a distance of $20 \mathrm{~km}$ near the North and South walls. We refer to the axis along the direction of the wind as the wind-axis.

\section{3) in the simulation CONST1.}

The eddy viscosities in both KEPS and KPP vary meridionally with maximum values in the eddying region ${ }^{2}$. This variability reflects the spatially varying turbulent mixing due to the wind stress (equation 14). To reproduce

\footnotetext{
${ }^{2}$ We interpret the eddying region as the region containing the eddies formed by the MLI. To estimate the meridional width of this region, we perform the following steps. We choose a certain flow parameter, the normalized relative vorticity $\zeta / f$, and obtain its probability density function (PDF) over a surface strip having a small meridional width, centered at the initial location of the front $(y=96 \mathrm{~km})$. We then gradually increase the width of the strip such that its center remains at $y=96 \mathrm{~km}$, until the PDF converges. For instance at inertial period 13 , the above procedure yields a width of approximately $40 \mathrm{~km}$ in all the simulations.
} 
such a meridional variability of the eddy viscosity, we allow $\nu_{\max }$ in CONST2

to vary with the wind stress as $\nu_{\max }(y)=0.035\left(\tau_{x}(y) / \max \left(\tau_{x}\right)\right)$.

\section{Results}

\subsection{Instantaneous fields}

The front goes unstable to MLI by the inertial period 7 and forms $\mathrm{O}(4-10$ $\mathrm{km}$ ) meanders (figure 3). The average size of the meanders is similar to the length-scale corresponding to an ageostrophic baroclinic instability (section 3.1). An ageostrophic cross-frontal circulation forms with $\mathrm{O}(100 \mathrm{~m} /$ day $)$ upwelling and downwelling along the edges of the meanders. The range of vertical velocities are similar in the four simulations with stronger peak downwelling compared to peak upwelling, which is consistent with earlier model results (Mahadevan and Tandon, 2006). By inertial period 13, the eddying region spans a meridional range of approximately $70-110 \mathrm{~km}$ with the largest eddies being $\mathrm{O}(10 \mathrm{~km}$ ) in diameter (figure 3$)$.

The periphery of these eddies show sharp density gradients due to active frontogenesis with the vertical component of the relative vorticity $(\zeta)$ being cyclonic on the denser side and anti-cyclonic on the lighter side of the fronts (figure 4). The rate of frontogenesis is expressed as $\frac{D}{D t}\left(\left|\vec{\nabla}_{h} B\right|^{2}\right)$ where $\left|\vec{\nabla}_{h} B\right|^{2}$ is the square of the resultant horizontal gradient of buoyancy $(B)$. Considering the rate of change of the buoyancy gradient due to the horizontal strain (Capet et al., 2008b; Hoskins, 1982) $\left(F_{a}\right)$, we get

$$
F_{a}=\underbrace{-\left[\left(\partial_{x} u \partial_{x} B+\partial_{x} v \partial_{y} B\right) \hat{\mathbf{i}}+\left(\partial_{y} u \partial_{x} B+\partial_{y} v \partial_{y} B\right) \hat{\mathbf{j}}\right]}_{\vec{Q}} \cdot \underbrace{\left(\partial_{x} B \hat{\mathbf{i}}+\partial_{y} B \hat{\mathbf{j}}\right.}_{\vec{\nabla}_{h} B}),
$$

where $\hat{\mathbf{i}}$ and $\hat{\mathbf{j}}$ are unit vectors along the $x$ and $y$ directions in the domain.

At the 10th inertial period, the top-view plots from all simulations (figure 4) show negative Ertel $\mathrm{PV}=(f \hat{k}+\vec{\zeta}) \cdot \nabla B$ along the periphery of the eddies at $10 \mathrm{~m}$ below the surface. While the initial condition in our simulations have negative PV to begin with, downfront winds further reduce the PV near the surface by the upward flux of PV through the surface (Thomas, 2005; Thomas and Lee, 2005). The surface boundary layer with negative PV is unstable to SI as shown by observations in the wintertime Gulf Stream (Thomas et al., 2013) and the Kuroshio front (D'Asaro et al., 2011; Nagai et al., 2012). Our analysis shows that our simulations resolve some of the SI 
modes (plot not shown), which is consistent with earlier studies that show SI can be potentially resolved even at non-LES resolutions (Bachman and Taylor, 2014). This raises the question whether SI can explain the enhanced dissipation occurring in our simulations.

The top-view plots from the four simulations (figure 4) show strong dissipation $(\epsilon)$ in localized regions on the periphery of the eddies where the PV is negative. However, other regions with strongly negative PV show weak dissipation, implying that SI alone cannot explain the spatial variability in the dissipation. Moreover, unlike LES where the turbulent cascade is resolved explicitly, our simulations do not capture all the downstream consequences of SI even though they have the resolution to resolve some of the SI modes. Hence, the interpretation of any existing spatial correlation between negative PV and epsilon in our simulations must necessarily differ from one explaining such a correlation in an LES. In section 4.4 we show that the spatial variability of $\epsilon$ results from variations in the relative alignment of the geostrophic and ageostrophic shear vectors, variations which themselves do not require the presence of negative PV.

\subsection{Contrasts between the instantaneous fields from the simulations}

Near the surface, the prescribed eddy viscosities and diffusivities in the simulations CONST1 and CONST2 are stronger than the ones in KEPS and KPP (figure 10d). Stronger eddy viscosity reduces the vertical shear $\left(S^{2}\right)$ within the mixed layer, whereas stronger eddy diffusivity reduces the vertical and horizontal buoyancy gradients by the following mechanisms: (i) strong diffusivity weakens the stratification $N^{2}$ by turbulent mixing, and (ii) weakens the lateral buoyancy gradients $\partial_{x} B$ and $\partial_{y} B$ by a continuous process of isopycnal slumping followed by vertical mixing (Rudnick and Martin, 2002).

360 Compared to KEPS and KPP, the simulations CONST1 and CONST2 show a narrower range of $S^{2}, N^{2}$ (figure $5 \mathrm{i}, \mathrm{j}, \mathrm{k}, \mathrm{l}$ ), lateral buoyancy gradients $\partial_{x} B$ and $\partial_{y} B$ (figure 5 e,f,g,h) and weaker horizontal deformation rate (not shown). Weaker buoyancy gradients reduce the rate of frontogenesis $\left(F_{a}\right)$, whereas weaker stratification and buoyancy gradients reduce the range of PV in the simulations CONST1 and CONST2 as noted in the top-view plots (figure 4). While the contrast between the results from CONST1 and CONST2 are minimal, CONST2 yields slightly more negative PV compared to CONST1 along the periphery of the meanders, as well as slightly stronger 
frontogenetic rates and stronger dissipation compared to CONST1. This sub-

tle difference between CONST1 and CONST2 is due to the meridional variability in the mixing coefficients in CONST2 (section 3.3), which makes the effective vertical viscosity (and diffusivity) in CONST2 less than CONST1 in the eddying region. The simulation KEPS yields both stronger frontogenetic rates and a larger range of PV compared to KPP due to weaker eddy viscosities and diffusivities in KEPS at a depth of $10 \mathrm{~m}$.

The peak dissipation in the simulation KEPS is stronger than that in CONST1 and CONST2 but weaker than that in KPP. This relative magnitude of the peak dissipation in KEPS, however, cannot be explained solely in terms of the relative magnitude of the shear squared since the parameterized $\epsilon$ in KEPS (2.2.2) is not equal to $\nu_{m} S^{2}$ as it is in the other simulations. Rather, the parameterized $\epsilon$ in KEPS is slightly less than $\nu_{m} S^{2}$ near the surface, as shown later in the subgrid EKE budget (section 4.5.2).

In the next section, we explore the spatial variability of $\epsilon$ in greater detail to characterize its variability.

\subsection{Spatial variability of the dissipation with flow properties}

The four simulations show a marked difference in the magnitudes of $\epsilon$, $N^{2}$ and $S^{2}$ at a depth of $10 \mathrm{~m}$ (figures $5 \mathrm{i}, \mathrm{j}, \mathrm{k}, 1$ ). As the vertical shear stress at the surface has to match the wind stress, the surface shear is inversely proportional to the eddy viscosity due to the downgradient parameterization of the stress-divergence term (equation 2c). This inverse proportionality at the surface is approximately valid at an intermediate depth within the shear-driven layer near the surface. Since the prescribed eddy viscosities in CONST1 and CONST2 near the surface are stronger than that in KEPS and KPP, stronger diffusion of momentum leads to reduced vertical shear in CONST1 and CONST2, and consequently weaker $\epsilon$ compared to KEPS and KPP (figure $5 \mathrm{i}, \mathrm{j}, \mathrm{k}, \mathrm{l}$ ).

Regardless of the type of the subgrid mixing parameterization, all simulations show certain similar trends in the scatter plots of $\epsilon$ with $\zeta, \mathrm{PV}, \partial_{x} B$, $\partial_{y} B, N^{2}$ and $S^{2}$, which are discussed below.

The scatter plot of $\zeta$ with PV, color coded with $\epsilon$ (figure 5a,b,c,d) shows that enhanced dissipation occurs mostly in the 4th quadrant characterized by cyclonic $\zeta$ and negative PV. The formation of cyclonic $\zeta$ and negative PV occurs due to the following mechanisms. In a submesoscale eddy field, the cyclonic $\zeta$ occurs on the denser side of the front and is associated with downwelling (Capet et al., 2008a; Mahadevan and Tandon, 2006; Thomas and Lee, 
2005; Thomas et al., 2008). Cyclonic $\zeta$ is further intensified by an enhancement in the along-front jet induced by the ageostrophic secondary circulation (ASC) during frontogenesis (Hoskins and Bretherton, 1972; Shakespeare and Taylor, 2013; Thomas and Lee, 2005), and vortex stretching by downwelling ${ }_{410}$ (Capet et al., 2008b; Hoskins and Bretherton, 1972). Negative PV is intensified along the periphery of the eddies by the upward flux of PV by downfront winds (Thomas and Lee, 2005; D'Asaro et al., 2011). The 4th quadrant in the scatter plots of PV and $\zeta$ (figure 5a,b,c,d) show enhanced dissipation at a few regions, but it also shows weak dissipation at other regions. This reaffirms our earlier inference (section 4.1) that SI alone cannot explain the occurrence of the enhanced dissipation seen in our simulations.

The 3rd quadrant (figure $5 \mathrm{e}, \mathrm{f}, \mathrm{g}, \mathrm{h}$ ), associated with negative $\partial_{x} B$ and $\partial_{y} B$ shows regions with both enhanced and weak dissipation, whereas the other quadrants show weak dissipation only. Due to thermal wind balance, negative $\partial_{x} B$ and $\partial_{y} B$ in our simulations produce a geostrophic shear directed towards the southeast.

The range of $S^{2}$ in the simulations KEPS and KPP at $10 \mathrm{~m}$ depth is nearly four times larger than that in CONST1 and CONST2 (figure 5i,j,k,l), which is an outcome of weaker eddy viscosities in KEPS and KPP (section 4.2). Similarly, weaker eddy diffusivities in KEPS and KPP form stronger $N^{2}$ compared to CONST1 and CONST2. In all the simulations, enhanced dissipation typically occurs in the regions with stable stratification and strong $S^{2}$, whereas the convectively unstable regions show weak dissipation and weak $S^{2}$ (figure $5 \mathrm{i}, \mathrm{j}, \mathrm{k}, \mathrm{l}$ ). In KEPS, however, many regions with strong $S^{2}$ and stable stratification with $R i<0.25$ show weak dissipation. This subtle difference in KEPS and the other three simulations is due to the difference between how $\epsilon$ is parameterized in KEPS and in the other simulations. Since $\epsilon=\nu_{m} S^{2}$ in CONST1, CONST2 and KPP, it is implicitly assumed in these simulations that $\epsilon$ is equal to the subgrid destruction of the resolved EKE.

435 However in KEPS, the use of a separate transport equation for $\epsilon$ (equation 5) allows $\nu_{m} S^{2}$ to be different from $\epsilon$. Indeed, we show later (section 4.5.2) that the $\epsilon$ near the surface in KEPS is slightly smaller than $\nu_{m} S^{2}$.

The spatial variability of $\epsilon$ with $N^{2}, S^{2}, \partial_{x} B, \partial_{y} B, \zeta$ and PV shows that enhanced dissipation in our simulations occurs at the regions with cyclonic $\zeta$, negative PV and a distinct frontal orientation such that the geostrophic shear is southeastward. In the next section we explain the underlying mechanism for this variability by examining the directions of the ageostrophic and geostrophic shear at these regions. 


\subsection{Asymmetry in spatial variability of $\epsilon$ over the periphery of an eddy}

445 6) show enhanced dissipation in localized regions along the edges characterized by strong lateral buoyancy gradients. The regions with enhanced dissipation are mostly on the right edge of the eddies where the stratification is stable, whereas the left edge of the eddies show weak dissipation and unstable ifying and restratifying edges respectively. In the following paragraphs, we explain the mechanisms behind the spatial variability in the stratification and $\epsilon$.

The ageostrophic flow near the surface is composed of (i) the wind-induced

Ekman advection directed at an acute angle to the right of the wind-axis (Ekman, 1905), and (ii) the cross-frontal circulation leading to frontogenesis. At the destratifying edge, the cross-frontal circulation is expected to be along the northwest due to the frontal orientation. However, we observe a southeastward flow at that edge (figure 8a1,b1), implying that the Ekman advection dominates over the cross-frontal circulation and moves water from the heavier to the lighter side (figure 8a1,b1). In contrast, at the restratifying edge, the direction of the Ekman advection is such that it is nearly orthogonal to the ageostrophic cross-frontal circulation (figure 8a2,b2).

To further explore the variability of enhanced dissipation on the frontal orientation, we discuss the individual components of the total subgrid shear production $P_{\text {total }}$, given by

$$
\begin{array}{r}
P_{\text {total }}=\underbrace{\nu_{m}\left[\left(\partial_{z} u_{a}\right)^{2}+\left(\partial_{z} v_{a}\right)^{2}\right]}_{P_{\text {ageo }}}+\underbrace{\nu_{m}\left[\left(\partial_{z} u_{g}\right)^{2}+\left(\partial_{z} v_{g}\right)^{2}\right]}_{P_{\text {geo }}} \\
+\underbrace{2 \nu_{m}\left(\partial_{z} u_{a} . \partial_{z} u_{g}+\partial_{z} v_{a} . \partial_{z} v_{g}\right)}_{P_{\text {cross }}},
\end{array}
$$

where the subscripts $a$ and $g$ denote the ageostrophic and geostrophic contributions respectively. The terms on the right hand side are the ageostrophic shear production $\left(P_{\text {ageo }}\right)$, geostrophic shear production $\left(P_{g e o}\right)$ and the cross term $\left(P_{\text {cross }}\right)$. We refer to $P_{\text {cross }}$ as the cross term because it contains products of the ageostrophic and geostrophic shear components.

The term $P_{\text {geo }}$ does not change significantly along the periphery of the eddies due to strong lateral gradients, but the term $P_{\text {cross }}$ is more positive

on the restratifying edge (figure 7 ) compared to the destratifying edge. This 
difference in the spatial variability of $P_{\text {cross }}$ strengthens the total shear production on the restratifying edge more compared to the destratifying edge. To explain this variability, we examine the relative alignment of the geostrophic

475 and ageostrophic shear vectors at both edges of the eddy (figure 8).

The ageostrophic and geostrophic shear at both the edges of the eddies are comparable in magnitude (figure 8a1,a2,b1,b2). The ageostrophic shear turns clockwise at the destratifying edge and opposes the geostrophic shear (figure 8a1,b1), thus reducing $P_{\text {total }}$. In contrast, at the restratifying edge, the ageostrophic shear turns clockwise and aligns with the geostrophic shear (figure $8 \mathrm{a} 2, \mathrm{~b} 2$ ). As a result, $P_{\text {total }}$ at the restratifying edge is enhanced. We see a similar trend at the periphery of the other eddies in our simulations.

The parameterized $\epsilon$ is weaker at the destratifying edge despite convective instability (figure 8a,b), which suggests that it is set by the shear production of EKE at that depth $(10 \mathrm{~m})$. This is consistent with the chosen depth lying within the shear-driven layer, as confirmed by further analysis of the resolved EKE budget (section 4.5).

\subsection{EKE budgets at resolved and subgrid scales}

In this section we study the influence of different vertical mixing parameterizations on the spatially averaged EKE budgets at resolved and subgrid scales, where the averaging is done over the eddying region. Since the averaged budgets in the simulations CONST2 and CONST1 are similar, we present only the results from CONST2, KEPS and KPP. 


\subsubsection{Resolved EKE budget}

The following equation represents the different terms of the resolved-scale EKE budget:

$$
\begin{aligned}
& \underbrace{\frac{\partial\left(u_{i}^{\prime} u_{i}^{\prime}\right)}{\partial t}}_{\text {ĖंE }}=\underbrace{\left(-u_{j} \frac{\partial}{\partial x_{j}}\left(u_{i}^{\prime} u_{i}^{\prime}\right)\right)}_{\text {advection }} \\
& \underbrace{-\left(\left(u_{i}^{\prime} u_{j}^{\prime}\right)\left(\frac{\partial u_{i}}{\partial x_{j}}\right)_{g e o}\right)-\left(\left(u_{i}^{\prime} u_{j}^{\prime}\right)\left(\frac{\partial u_{i}}{\partial x_{j}}\right)_{\text {ageo }}\right)}_{\text {geo. shear production }\left(\mathrm{Pgr}_{\mathrm{gr}}\right) \text { and ageo. shear production }(\mathrm{Par})} \\
& +\underbrace{\left(B^{\prime} u_{i}^{\prime}\right)_{i=3}}_{\text {buoyancy production } \mathrm{B}_{\mathrm{r}}}-\underbrace{\frac{1}{\rho_{0}} \frac{\partial}{\partial x_{i}}\left(p^{\prime} u_{i}^{\prime}\right)}_{\text {pressure transport }} \\
& +\underbrace{\left(\tau_{i j} \frac{\partial u_{i}}{\partial x_{j}}\right)}_{\text {interscale transfer }\left(\epsilon_{\mathrm{I}}\right)}
\end{aligned}
$$

where $u_{i}$ is the velocity along the direction $i$. The primed quantities are fluctuations from the zonally averaged quantities. The terms on the RHS are the advection, geostrophic shear production of resolved EKE $\left(P_{g r}\right)$, ageostrophic shear production of resolved EKE $\left(P_{a r}\right)$, buoyancy production of resolved EKE $\left(B_{r}\right)$, pressure transport and interscale transfer $\left(\epsilon_{I}\right)$. The interscale transfer, defined as the contraction of the subgrid-scale stress tensor with the resolved strain-rate tensor, is the rate at which EKE is transferred from the resolved to the subgrid scales. While this term is a sink for the resolved EKE, it appears as a source in the subgrid EKE budget in the form of the subgrid shear production (equation 18).

In a horizontally homogenous flow, Monin-Obukhov (MO) scaling (Lombardo and Gregg, 1989; Shay and Gregg, 1984; Thorpe, 2007) predicts the shear production within the shear-driven layer (or MO layer) as $P=u_{*}^{3} /(\kappa z)$, where $u_{*} \approx \sqrt{\tau_{0} / \rho}$ is the surface friction velocity. The depth of the MO layer (MO depth) is $L_{M O}=u_{*}^{3} / \kappa B_{c}$ where $B_{c}$ is the buoyancy flux by atmospheric cooling. Since the dissipation and shear production are in leading order balance within the MO layer, the dissipation $\epsilon$ scales as $u_{*}^{3} /(\kappa z)$. For mixed-layer fronts forced with a downfront wind stress but no atmospheric cooling, earlier studies have raised the possibility to substitute the Ekman 
buoyancy flux (EBF) for the cooling flux $B_{c}$ in the expression for $L_{M O}$ (Ra515 machandran et al., 2013; Thomas, 2005), such that $L_{M O}=u_{*}^{3} /(\kappa \mathrm{EBF})$ where $\mathrm{EBF}=\left|\partial_{y} B\right| \tau_{0} / \rho f$ (Thomas, 2005). The full implications of replacing $B_{c}$ by EBF for similarity-scaling theory are beyond the scope of the present study. Here we only seek to determine whether such a replacement helps to explain the vertical structure of the resolved EKE budgets.

Using a representative value of wind stress $\tau_{0}=0.1 \mathrm{~N} / \mathrm{m}^{2}$, we obtain $u_{*}=10^{-2} \mathrm{~m} / \mathrm{s}$ within the eddy field. Using a representative value of $\left|\partial_{y} B\right| \approx$ $10^{-7} \mathrm{~s}^{-2}$ within the eddying region, we get $\mathrm{EBF} \approx 10^{-7} \mathrm{~m}^{2} \mathrm{~s}^{-3}$ and $L_{M O} \approx$ $26 \mathrm{~m}$. The resolved EKE budgets in the simulations KEPS and KPP show a leading order balance between $P_{a r}$ and $\epsilon_{I}$ within the upper $25 \mathrm{~m}$ (figure 9 ), which is consistent with the above calculation for $L_{M O}$. However, such a balance is not observed in CONST1 and CONST2 since stronger eddy viscosities near the surface (figure 10d) lead to considerably reduced vertical shear, thereby reducing the magnitudes of $P_{a r}$ and $\epsilon_{I}$. This results in all the terms of the resolved EKE budget to have the same order of magnitude, which disrupts the leading order balance between $P_{a r}$ and $\epsilon_{I}$ seen in the other simulations. The resulting vertical structure in CONST1 and CONST2 does not have a well-defined shear layer and a corresponding MO depth.

The resolved EKE budget from CONST2 is markedly different from that in KEPS and KPP (figure 9). Near the surface, the terms $P_{a r}$ and $\epsilon_{I}$ are in a leading order balance in the simulations KEPS and KPP. But in CONST2, these two terms are an order of magnitude smaller than those in KEPS and KPP, forming a three-way balance along with the vertical pressure transport near the surface (figure 9a). There is also an additional but minor contribution from the geostrophic shear production. This contrast between CONST2 and KEPS or KPP is due to the influence of stronger eddy viscosities and diffusivities in CONST2 within the top $20 \mathrm{~m}$ (figure 9a,b,c).

Below $20 \mathrm{~m}$ (figure $9 \mathrm{~d}, \mathrm{e}, \mathrm{f}$ ), the buoyancy production $B_{r}$ in CONST2 is an order of magnitude weaker than that in KEPS and KPP, and hence not the dominant source term. A positive $B_{r}$ represents the restratification associated with the conversion of APE to EKE by the MLI. In CONST2 (and CONST1), the eddy diffusivity does not change with time, which has the following consequences: (i) vertical diffusion of buoyancy by strong eddy diffusivities (figure 10d) slows the rate of shallowing of the mixed layer by the MLI induced restratification, and (ii) the repeated isopycnal slumping and vertical mixing due to strong eddy diffusivity reduces the lateral buoyancy gradients in the eddying region (Rudnick and Martin, 2002) which are reser- 
voirs of APE. The outcome is reduced rate of restratification in CONST1 and CONST2. On the other hand, the shallowing of the mixed layer by MLI-induced restratification in KEPS and KPP reduce the eddy diffusivities (figure 10d), which facilitate further restratification and mixed-layer shallowing at later times (figure 10a,b,c). Since the eddy diffusivity is influential in the reduction of the lateral buoyancy gradients (Rudnick and Martin, 2002), weaker eddy diffusivity leads to stronger lateral gradients and thereby higher APE in KEPS and KPP. Higher APE results in a stronger restratification rate and consequently larger production of the resolved EKE by $B_{r}$ (figure 9e,f). Due to larger EKE production, the summation of the EKE-budget terms show a net increase in the EKE in KEPS and KPP, whereas in CONST1 and CONST2 the EKE reduces due to $\epsilon_{I}$ and the vertical pressure transport (figure 9a).

565 There are important similarities between the vertical structures of the resolved EKE budget in KEPS and KPP, and the TKE budget in LES simulations of a mixed-layer front forced with downfront winds (Taylor and Ferrari, 2010). In their simulations, they note a shear-driven layer near the surface overlying a buoyancy-driven layer and a forced SI layer at the bottom of the stratified boundary layer. The KEPS and KPP simulations in our studies show the shear-driven layer atop the buoyancy-driven layer as discussed earlier, but not a forced SI layer. It is perhaps likely that in order to observe the kind of well-defined forced-SI layer seen in the LES study (Taylor and Ferrari, 2010), we would require LES-like grid resolutions. Hence, based on the 575 above qualitative comparison, we infer that the simulations KEPS and KPP produce more realistic EKE budgets compared to CONST1 and CONST2.

\subsubsection{Subgrid EKE budget}

Among the different subgrid mixing parameterizations considered in this study, only the $k-\epsilon$ allows us to explore the subgrid EKE budget since it 
governing the evolution of $k$ are shown below:

$$
\begin{array}{r}
\frac{\partial}{\partial t} k=\underbrace{\frac{\partial}{\partial x_{i}}\left(\frac{\nu_{m}}{\sigma_{k}} \frac{\partial}{\partial x_{i}} k\right)_{i=3}-\left(u_{i} \frac{\partial}{\partial x_{i}} k\right)_{i=1,2}}_{\text {downgradient transfer } \mathrm{D}_{\mathrm{k}}} \underbrace{\left(-u_{i} \frac{\partial}{\partial x_{i}} k\right)_{i=3}}_{\text {Horizontal advection } \mathrm{A}_{\mathrm{h}}} \underbrace{\left(-\tau_{i j} \frac{\partial u_{i}}{\partial x_{j}}\right)_{i=1,2 ; j=3}}_{\text {Vertical advection } \mathrm{A}_{\mathrm{v}}} \\
+\underbrace{\left(\tau_{i}^{B}\right)_{i=3}}_{\text {shear production } \mathrm{P}_{\mathrm{s}}=\nu_{\mathrm{m}} \mathrm{S}^{2}}, \underbrace{\epsilon}_{\text {subgrid dissipation }},
\end{array}
$$

where $u_{i}$ is the resolved velocity and $\tau_{i}^{B}$ is the subgrid buoyancy production. The terms $A_{h}$ and $A_{v}$ are the horizontal and vertical advection of $k$ by the resolved-scale velocities respectively. The term $P_{s}$ denotes the production of $k$ at subgrid scales through the contraction of the subgrid stress and the resolved-scale shear. Note that $P_{s}$ is identical in magnitude but opposite in sign to the interscale transfer term $\epsilon_{I}$ (equation 17), the sink in the resolved EKE budget. The term $B_{s}$ is a downgradient parameterization for the subgrid buoyancy flux (Burchard et al., 1999; Rodi, 1976). The term $\epsilon$ denotes the dissipation of EKE at the smallest scales, which is parameterized in KEPS through a separate equation (5). The terms $P_{s}$ and $B_{s}$ are parameterized based on the resolved shear and stratification respectively, and can be obtained in the other subgrid mixing parameterizations as well.

The subgrid EKE budget for KEPS averaged over the eddying region shows a leading order balance between $P_{s}$ and $\epsilon$ within the entire mixed layer (figure 11a). The term $P_{s}$ is larger than $\epsilon$ near the surface, implying a net increase of $k$ in the mixed layer. The downgradient transport term $D_{k}$ is negligible except within the top $10 \mathrm{~m}$ where the vertical gradient of $k$ is the largest. It, however, is still smaller than the leading-order terms by an order of magnitude. The horizontal and vertical advection of EKE are negligible. The subgrid buoyancy production $B_{s}$ is negative within the entire mixed layer, and is smaller than the leading order terms by an order of magnitude (figure 11a). A comparison of the magnitudes of $B_{s}$ from the subgrid EKE budget and $B_{r}$ from the resolved EKE budget in the 
buoyancy-driven layer reveals that $B_{s}$ is almost an order of magnitude less than $B_{r}$. This difference is qualitatively similar to the LES results from a wind-forced mixed-layer front without Stokes-drift (Hamlington et al., 2014). In their studies, they split their resolved buoyancy flux into a high-pass $(9.6 \mathrm{~m}-400 \mathrm{~m})$ component which represents the small-scale buoyancy flux, and a low pass $(400 \mathrm{~m}-20 \mathrm{~km})$ component which represents the submesoscale buoyancy flux. They found that the low-pass buoyancy flux which represents the eddy-induced restratification, is positive and can be 4 times larger than the high-pass buoyancy flux which is negative and represents the small-scale processes. We infer that the ratio of the resolved to the subgrid buoyancy

flux in the KEPS simulation is qualitatively similar but not identical to that seen in the LES study.

At $\mathrm{O}(1-10 \mathrm{~km})$ or larger scales where the ABI is resolved, positive buoyancy flux in KEPS (figure 9) reflects eddy-induced restratification due to the conversion of APE to EKE. However at subgrid scales, the downgradient parameterization for the buoyancy flux (equation 18) makes it a sink (negative) of $k$ during stable stratification and a source (positive) of $k$ during unstable stratification. A comparison of $B_{s}$ from the four simulations averaged over the eddying region shows that it is the most negative for the simulation CONST2 (figure 11b). In CONST2 and CONST1, since the eddy diffusivity does not change with time, the increase in $N^{2}$ due to the ABI results in the intensification of the negative subgrid buoyancy flux. However, in KEPS and $\mathrm{KPP}$, the increase in stratification due to ABI is compensated by the reduction in the eddy diffusivity, resulting in a negligible change in the subgrid buoyancy flux at later times.

\section{Conclusion}

This study has explored: (i) the influence of different vertical eddy viscosity parameterizations on the resolved submesoscale eddy field forced with downfront winds, (ii) the spatial variability of the dissipation in a submesoscale eddy field and the mechanisms that enhance the dissipation in localized regions within the eddy field, and (iii) the vertical structure of the subgrid EKE budget. We use the 3D ocean model PSOM and estimate the vertical eddy viscosities and diffusivities using three different types of $1 \mathrm{D}$ vertical mixing parameterizations: (i) $k-\epsilon$, (ii) KPP and (iii) an Ekman-layer based parameterization. 
Our study shows that the magnitude of the parameterized dissipation, averaged over the eddy field, varies with the type of the subgrid mixing parameterization. For the models that prescribe constant vertical eddy viscosities, stronger eddy viscosity leads to weaker dissipation. However for the models that dynamically estimate eddy viscosities based on the water column properties, the ABI induced restratification reduces the eddy viscosities within the mixed layer, resulting in stronger dissipation.

Our simulations show that the rate of restratification by MLI in a resolved submesoscale eddy field depends on the type of the chosen subgrid mixing parameterization. Constant eddy-viscosity parameterizations with $\mathrm{O}\left(10^{-2} \mathrm{~m}^{2} \mathrm{~s}^{-1}\right)$ values weaken the lateral buoyancy gradients by repeated slumping of the isopycnals and vertical mixing (Rudnick and Martin, 2002), thus weakening the restratification by MLI. For mixing parameterizations that dynamically estimate the turbulent mixing coefficients based on the water column properties, the MLI induced restratification reduces the eddy diffusivities, which further facilitates the restratification and shallowing of the mixed layer at later times. Since the $k-\epsilon$ parameterization yields weaker eddy diffusivities than the KPP, the mixed layer in KEPS shallows more rapidly than that in KPP. In contrast, since the $\mathrm{O}\left(10^{-2} \mathrm{~m}^{2} \mathrm{~s}^{-1}\right)$ eddy diffusivities prescribed in CONST1 and CONST2 remain unaffected by the restratification, the mixed layer in CONST1 and CONST2 shallows less rapidly compared to KEPS and KPP.

Our study further shows a spatial variability in the parameterized dissipation in a submesoscale eddy field forced with downfront winds. The dissipation is enhanced at the restratifying edge but weak at the destratifying edge. This spatial variability is the consequence of the relative alignment of the shear vectors at the two edges of the eddies. At the restratifying edge, the ageostrophic shear turns clockwise and aligns with the geostrophic shear, resulting in stronger shear production. In contrast, at the destratifying edge, the two shear vectors oppose each other, which weakens the shear production. The outcome is enhanced dissipation at the restratifying edge and weak dissipation at the destratifying edge since the magnitude of the parameterized dissipation is set by the shear production within the shear-driven layer irrespective of stable or unstable stratification.

Near the surface the dissipation and ageostrophic shear production in the simulations KEPS and KPP are an order of magnitude larger than those in CONST1 and CONST2. This difference is the consequence of the diffusion of the vertical shear by stronger eddy viscosities in CONST1 and CONST2 
than those generated by the $k-\epsilon$ and KPP mixing models. The consequence of weakened vertical shear is observed in the resolved EKE budget for the simulations CONST1 and CONST2 where the leading order balance is between the ageostrophic shear production, subgrid dissipation and vertical pressure transport with a minor contribution from the geostrophic shear production. This balance differs from that in KEPS and KPP where the EKE budget shows a shear-driven layer within the top $25 \mathrm{~m}$ and a buoyancy-driven layer underneath. The depth where the buoyancy production balances the shear production is approximately equal to the MO layer depth obtained by replacing the cooling flux by the Ekman buoyancy flux due to downfront winds (Thomas, 2005).

The subgrid EKE budget in KEPS shows a leading order balance between the subgrid shear production and the subgrid dissipation. While this leading order balance exists throughout the mixed layer, there is a net increase in the production of subgrid EKE near the surface since the subgrid shear production exceeds the dissipation. The magnitude of the parameterized subgrid buoyancy production in the buoyancy-driven region is an order of magnitude smaller than the resolved buoyancy production of EKE.

The parameterizations used in this study for vertical mixing consider the surface momentum flux, the depth of the mixed layer and the vertical shear and stratification for estimating the eddy viscosities. However, other sources of small-scale turbulence like breaking waves (Craig and Banner, 1994) and Stokes shear due to surface waves (Haney et al., 2015), also influence the subgrid momentum and buoyancy parameterizations for the resolved flow field. The inclusion of these effects into existing mixing parameterizations may have a potential influence on the larger $\mathrm{O}(1 \mathrm{~km}-100 \mathrm{~km})$ scale processes. It is of interest to explore how these effects influence the spatial variability of the parameterized dissipation and the EKE budget in a submesoscale eddy field.

\section{Acknowledgments}

This research was supported by the Office of Naval Research Grant (N0001409-1-0196). We acknowledge the computational support from the Massachusetts 710 Green High Performance Computing Cluster for performing the simulations. We thank the reviewers of this manuscript for their valuable inputs which led to significant improvements of the manuscript. We also thank Hans Burchard at the Leibniz Institute for Baltic Sea Research, Miles Sundermeyer 
at School of Marine Science at University of Massachusetts Dartmouth and

715 Baylor Fox-Kemper at Brown University for their valuable comments and suggestions.

\section{References}

Bachman, S. D., Taylor, J. R., 2014. Modelling of partially-resolved oceanic symmetric instability. Ocean Modelling 82, 15-27.

Boccaletti, G., Ferrari, R., Fox-Kemper, B., 2007. Mixed Layer Instabilities and Restratification. J. Phys. Oceanogr. 37 (9), 2228-2250.

Burchard, H., Bolding, K., 2001. Comparative Analysis of Four SecondMoment Turbulence Closure Models for the Oceanic Mixed Layer. J. Phys. Oceanogr. 31 (8), 1943-1968.

Burchard, H., Bolding, K., Villarreal, M. R., 1999. GOTM - A general ocean turbulence model: Theory, implementation and test cases. Tech. rep., European Commission.

Canuto, V. M., Howard, A., Cheng, Y., Dubovikov, M. S., 2001. Ocean turbulence. Part I: One-point closure model-momentum and heat vertical diffusivities. J. Phys. Oceanogr. 31 (6), 1413-1426.

Capet, X., McWilliams, J. C., Molemaker, M. J., Shchepetkin, A. F., 2008a. Mesoscale to submesoscale transition in the California Current System. Part I: Flow structure, eddy flux, and observational tests. J. Phys. Oceanogr. 38 (1), 29-43.

Capet, X., McWilliams, J. C., Molemaker, M. J., Shchepetkin, A. F., 2008b. Mesoscale to Submesoscale transition in the California Current system. Part II: Frontal Processes. J. Phys. Oceanogr. 38 (1), 44-64.

Capet, X., McWilliams, J. C., Molemaker, M. J., Shchepetkin, A. F., 2008c. Mesoscale to Submesoscale Transition in the California Current System. Part III: Energy Balance and Flux. J. Phys. Oceanogr. 38 (10), 2256-2269.

Charney, J. G., 1971. Geostrophic turbulence. J. Atm. Sci 28 (6), 1087-1095.

Craig, P. D., Banner, M. L., 1994. Modeling wave-enhanced turbulence in the ocean surface layer. J. Phys. Oceanogr. 24 (12), 2546-2559. 
D'Asaro, E., Lee, C., Rainville, L., Harcourt, R., Thomas, L. N., 2011. 745 Enhanced Turbulence and Energy Dissipation at Ocean Fronts. Science 332 (6027), 318-322.

Durski, S. M., Glenn, S. M., Haidvogel, D. B., 2004. Vertical mixing schemes in the coastal ocean: Comparison of the level 2.5 Mellor-Yamada scheme with an enhanced version of the K profile parameterization. J. Geophys. Res. 109 (C1).

Ekman, V. W., 1905. On the influence of the earth's rotation on ocean currents. Ark. Mat. Astron. Fys. 2, 1-53.

Fox-Kemper, B., Danabasoglu, G., Ferrari, R., Griffies, S. M., Hallberg, R. W., Holland, M. M., Maltrud, M. E., Peacock, S., Samuels, B. L., 2011. Parameterization of mixed layer eddies. III: Implementation and impact in global ocean climate simulations. J. Phys. Oceanogr. 39 (1), 61-78.

Fox-Kemper, B., Ferrari, R., 2008. Parameterization of Mixed Layer Eddies. Part II: Prognosis and Impact. J. Phys. Oceanogr. 38 (6), 1166-1179.

Fox-Kemper, B., Ferrari, R., Hallberg, R. W., 2008. Parameterization of Mixed Layer Eddies. Part I: Theory and Diagnosis. J. Phys. Oceanogr. 38 (6), 1145-1165.

Gibson, M. M., Launder, B. E., 1976. On the calculation of horizontal, turbulent, free shear flows under gravitational influence. Journal of Heat Transfer 98 (1), 81-87.

Grant, A. L. M., Belcher, S. E., 2009. Characteristics of Langmuir turbulence in the ocean mixed layer. J. Phys. Oceanogr. 39 (8), 1871-1887.

Hamlington, P. E., Roekel, L. P. V., Fox-Kemper, B., Julien, K., Chini, G. P., 2014. Langmuir-Submesoscale Interactions: Descriptive Analysis of Multiscale Frontal Spindown Simulations. J. Phys. Oceanogr. 44 (9), 2249-2272.

Haney, S., Fox-Kemper, B., Julien, K., Webb, A., 2015. Symmetric and Geostrophic Instabilities in the Wave-Forced Ocean Mixed Layer. J. Phys. Oceanogr. 
Hoskins, B. J., 1982. The mathematical theory of frontogenesis. Annu. Rev. $775 \quad$ Fluid Mech. 14 (1), 131-151.

Hoskins, B. J., Bretherton, F. P., 1972. Atmospheric frontogenesis models: Mathematical formulation and solution. J. Atmos. Sci. 29 (1), 11-37.

Kato, H., Phillips, O. M., 1969. On the penetration of a turbulent layer into stratified fluid. J. Fluid Mech. 37 (4), 643-655.

Klein, P., Hua, B. L., Lapeyre, G., Capet, X., Gentil, S. L., Sasaki, H., 2008. Upper ocean turbulence from high-resolution 3D simulations. J. Phys. Oceanogr. 38 (8), 1748-1763.

Lapeyre, G., Klein, P., Hua, B. L., 2006. Oceanic Restratification Forced by Surface Frontogenesis. J. Phys. Oceanogr. 36 (8), 1577-1590.

Large, W. G., McWilliams, J. C., Doney, S. C., 1994. Oceanic vertical mixing: a review and a model with nonlocal boundary layer parameterisation. Rev. Geophys. 32 (4), 363-404.

Leonard, B. P., 1988. Simple high-accuracy resolution program for convective modelling of discontinuities. International Journal for Numerical Methods in Fluids 8 (10), 1291-1318.

Lombardo, C., Gregg, M., 1989. Similarity scaling of viscous and thermal dissipation in a convecting surface boundary layer. J. Geophys. Res. 94 (C25), 6273-6284.

Mahadevan, A., 2006. Modeling vertical motion at ocean fronts: Are nonhydrostatic effects relevant at submesoscales? Ocean Modelling 14 (3), $222-240$.

Mahadevan, A., D'Asaro, E., Lee, C., Perry, M. J., 2012. Eddy-Driven Stratification Initiates North Atlantic Spring Phytoplankton Blooms. Science 337 (6090), 54-58.

Mahadevan, A., Tandon, A., 2006. An analysis of mechanisms for submesoscale vertical motion at ocean fronts. Ocean Modelling 14 (3), 241-256.

Mahadevan, A., Tandon, A., Ferrari, R., 2010. Rapid changes in mixed layer stratification driven by submesoscale instabilities and winds. J. Geophys. Research: Oceans 115 (C3), c03017. 
Shakespeare, C. J., Taylor, J. R., 2013. A generalized mathematical model of geostrophic adjustment and frontogenesis: Uniform potential vorticity. J. Fluid Mech. 736, 366-413.

Shay, T. J., Gregg, M. C., 1984. Turbulence in an oceanic convective mixed 830

Skyllingstad, E. D., Denbo, D. W., 1995. An ocean large-eddy simulation of Langmuir circulations and convection in the surface mixed layer. J. Geophys. Res. 100 (C5), 8501-8522.

Stone, P. H., 1966. On Non-Geostrophic Baroclinic Instability. J. Atm. Sci. 835 in buoyancy-driven fronts. Ocean Modelling 83, 43-62.

Mellor, G. L., Yamada, T., 1982. Development of a tubulence closure model for geophysical fluid problems. Reviews of Geophysics and Space Physics 20 (4), 851-875. H., 2015. The impact of advection schemes on restratifiction due to lateral shear and baroclinic instabilities. Ocean Modelling 94, 112-127.

Molemaker, M. J., McWilliams, J. C., Yavneh, I., 2005. Baroclinic instability and loss of balance. J. Phys. Oceanogr. 35 (9), 1505-1517.

Nagai, T., Tandon, A., Yamazaki, H., Doubell, M. J., Gallager, S., 2012. Direct observations of microscale turbulence and thermohaline structure in the Kuroshio Front. J. Geophys. Res. 117 (C8).

Ramachandran, S., Tandon, A., Mahadevan, A., 2013. Effect of subgridscale mixing on the evolution of forced submesoscale instabilities. Ocean

Rodi, W., 1976. A new algebraic relation for calculating the Reynolds stresses. Gesellschaft Angewandte Mathematik und Mechanik Workshop Paris France 56, 219.

Rudnick, D. L., Martin, J. P., 2002. On the horizontal density ratio in the upper ocean. Dyn. Atm. Ocean. 36 (1), 3-21.

layer. Nature 310, 282-285.

$23(4), 390-400$.

Marques, G. M., Özgökmen, T. M., 2014. On modeling turbulent exchange 
Stone, P. H., 1970. On Non-Geostrophic Baroclinic Instability: Part II. J. Atm. Sci. 27 (5), 721-726.

Tandon, A., Garrett, C., 1994a. Geostrophic Adjustment and Restratification of a Mixed Layer with Horizontal Buoyancy Gradients Above a Stratified Layer. J. Phys. Oceanogr. 25 (10), 2229-2241.

Tandon, A., Garrett, C., 1994b. Mixed Layer Restratification Due to a Horizontal Density Gradient. J. Phys. Oceanogr. 24 (6), 1419-1424.

Taylor, J. R., Ferrari, R., 2009. On the equilibration of a symmetrically unstable front via a secondary shear instability. J. Fluid Mech. 622, 103113.

Taylor, J. R., Ferrari, R., 2010. Buoyancy and wind-driven convection at a mixed-layer density fronts. J. Phys. Oceanogr. 40 (6), 1222-1242.

Taylor, J. R., Ferrari, R., 2011. Ocean fronts trigger high latitude phytoplankton blooms. Geophys. Res. Lett. 38, 123601.

Thomas, L. A., 2005. Destruction of Potential Vorticity by Winds. J. Phys. Oceanogr. 35 (12), 2457-2466.

Thomas, L. A., Tandon, A., Mahadevan, A., 2008. Submesoscale ocean processes and dynamics. Ocean Modeling in an Eddying Regime, Geophys. Monogr. Ser. 177, 17-38.

Thomas, L. N., 2008. Formation of intrathermocline eddies at ocean fronts by wind-driven destruction of potential vorticity. Dyn. Atm. Ocean. 45 (3), 252-273.

Thomas, L. N., Lee, C. M., 2005. Intensification of Ocean Fronts by DownFront Winds. J. Phys. Oceanogr. 35 (6), 1086-1102.

Thomas, L. N., Taylor, J. R., 2010. Reduction of the usable wind-work on the general circulation by forced symmetric instability. Geophys. Res. Lett. $37(18)$.

Thomas, L. N., Taylor, J. R., Ferrari, R., Joyce, T. M., 2013. Symmetric instability in the Gulf Stream. Deep Sea Research Part II: Topical Studies in Oceanography 91, 96-110. 
Thorpe, S. A., 2007. An introduction to ocean turbulence. Cambridge University Press.

Umlauf, L., Burchard, H., 2005. Second-order turbulence closure models for geophysical boundary layers. A review of recent work. Cont. Shelf. Res. $25(7), 795-827$.

Table 1: Simulation parameters

\begin{tabular}{|l|l|}
\hline Domain size & $96 \times 192 \times 0.5 \mathrm{~km}$ \\
\hline Zonal and meridional eddy viscosities & $0 \mathrm{~m}^{2} \mathrm{~s}^{-1}$ \\
\hline $\begin{array}{l}\text { Maximum Lateral buoyancy gradient } \\
\text { at } t=0\end{array}$ & $1.3 \times 10^{-7} \mathrm{~s}^{-2}$ \\
\hline Buoyancy frequency $N^{2}$ & $1.5 \times 10^{-6} \mathrm{~s}^{-2}$ \\
\hline Time step & $216 \mathrm{~seconds}$ \\
\hline Horizontal Grid Resolution & $0.5 \mathrm{~km}$ \\
\hline Vertical Grid Resolution & $\begin{array}{l}\mathrm{O}(1 \mathrm{~m}) \text { near surface, } \\
\mathrm{O}(10 \mathrm{~m}) \text { at the bottom }\end{array}$ \\
\hline Wind stress $\left(\tau_{x}\right)$ & $\begin{array}{l}0.1 \mathrm{~N} / \mathrm{m}^{2} \text { at } y=96 \mathrm{~km}, \text { tapering } \\
\text { sinusoidally towards the walls }\end{array}$ \\
\hline Coriolis parameter $f$ & $7.7 \times 10^{-5} \mathrm{~s}^{-1}$ \\
\hline Mixed-layer depth $(t=0)$ & $100 \mathrm{~m}$ \\
\hline
\end{tabular}

Table 2: Simulation types

\begin{tabular}{|l|l|}
\hline Simulation & Mixing Parameterization \\
\hline CONST1 & $\begin{array}{l}\text { Ekman parameterization, } \gamma_{1}=1.68, \gamma_{2}=0.6, \\
k z_{\max }=0.035 \mathrm{~m}^{2} \mathrm{~s}^{-1}\end{array}$ \\
\hline CONST2 & $\begin{array}{l}\text { EKman parameterization, } \gamma_{1}=1.68, \gamma_{2}=0.6, \\
\text { meridionally varying } k z_{\text {max }} \text { with a maximum of } \\
\\
0.035 \mathrm{~m}^{2} \mathrm{~s}^{-1} \text { at } y=96 \mathrm{~km} .\end{array}$ \\
\hline KEPS & $k-\epsilon$ mixing parameterization \\
\hline KPP & KPP mixing scheme \\
\hline
\end{tabular}



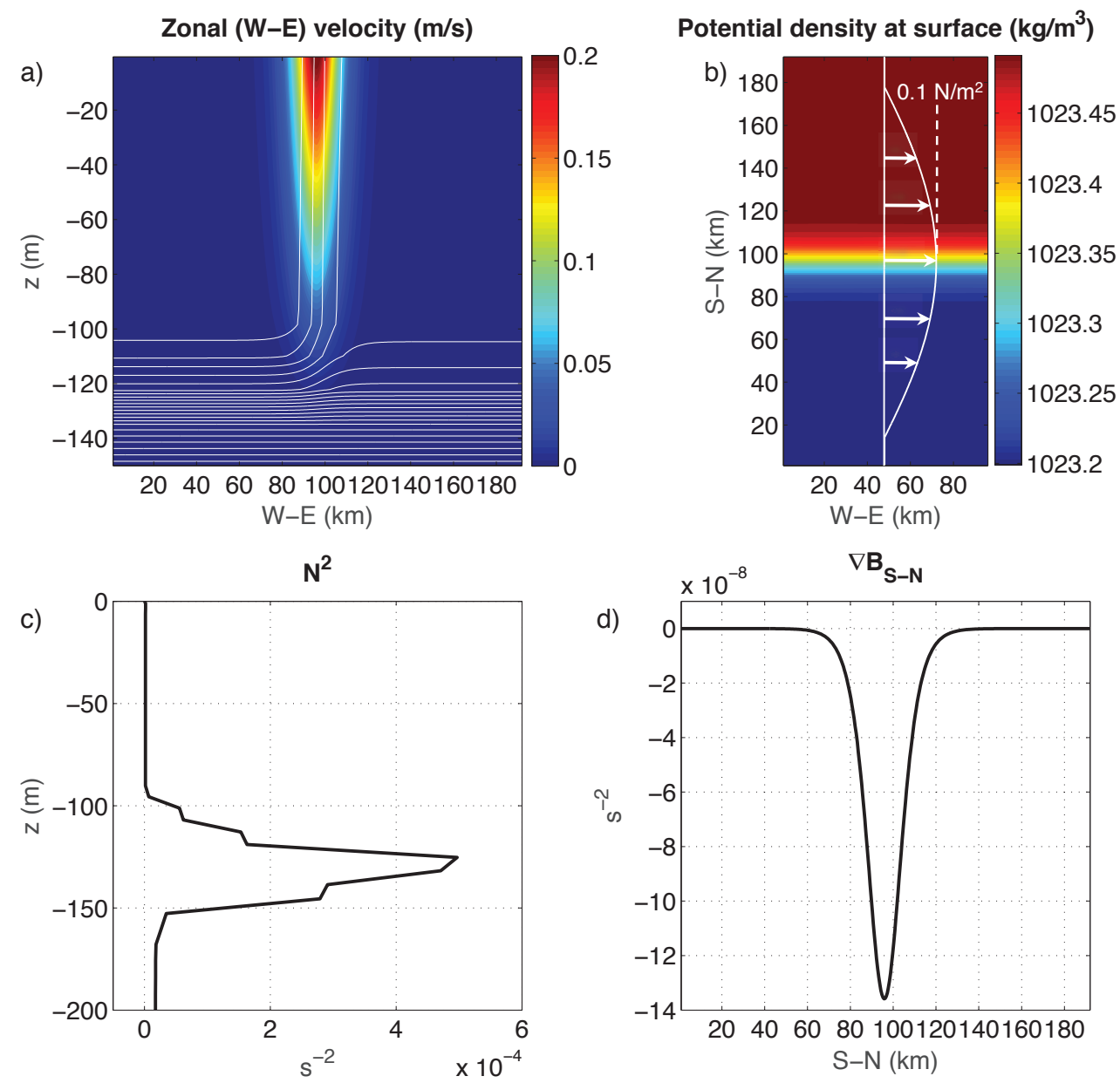

Figure 1: a) Meridional transect at $x=48 \mathrm{~km}$ showing the zonal velocity due to thermal wind balance, with isopycnals (white lines). b) Surface snapshot of the potential density $\left(\sigma_{\theta}\right)$ with the meridionally varying wind stress (white arrows) that tapers near the South and North walls. c) Profile of buoyancy frequency $N^{2}$ averaged over the mixed-layer front. d) Meridional buoyancy gradient in the mixed layer. 

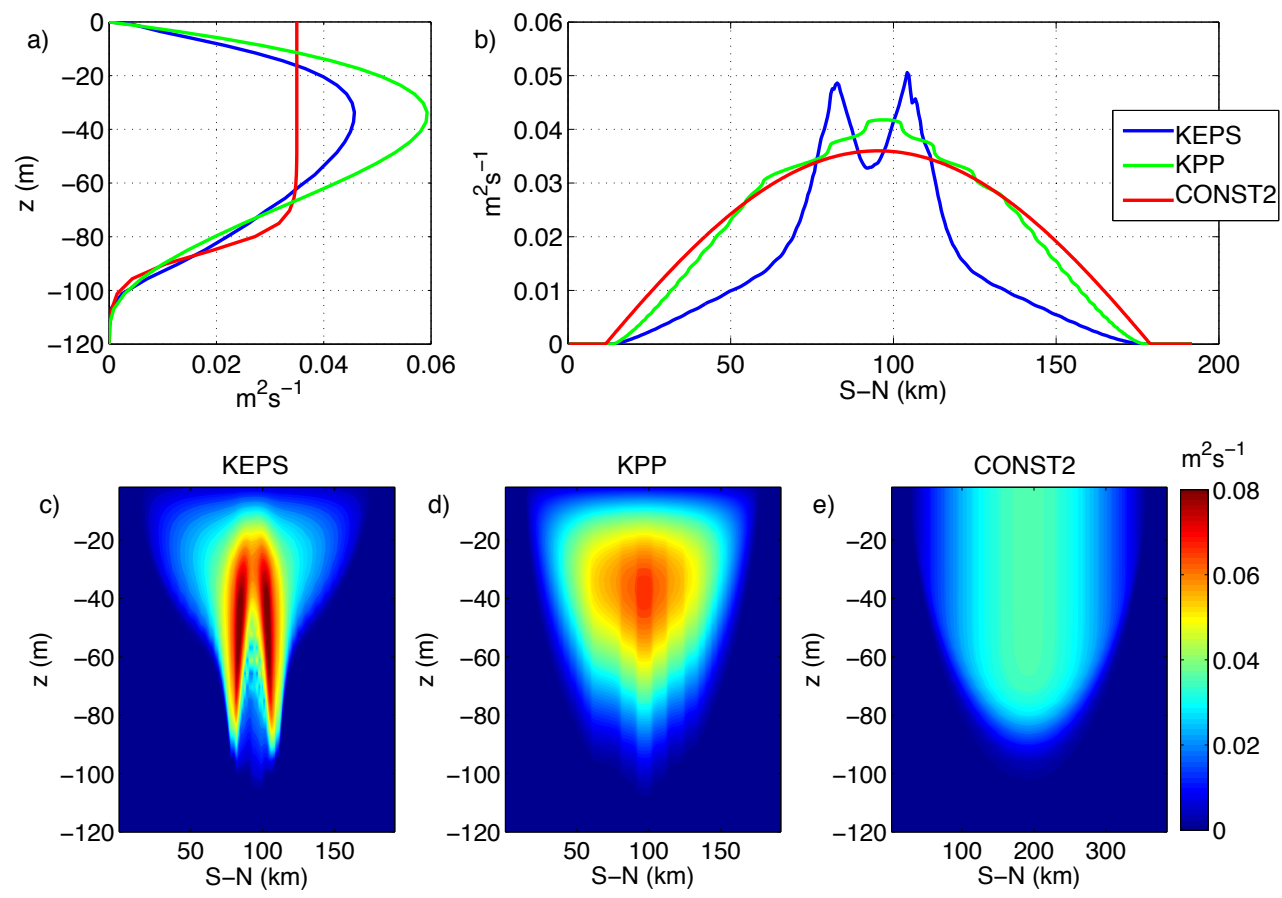

Figure 2: a) Profiles of eddy viscosity $\nu_{m}$ spatially averaged over the mixed-layer front for KEPS, KPP and CONST2. Plot b) shows $\nu_{m}$ averaged zonally and vertically from the surface to $70 \mathrm{~m}$ for KEPS, KPP and CONST2. Plots c), d) and e) are zonally averaged transects of $\nu_{m}$ for KEPS, KPP and CONST2 respectively. All plots are shown at inertial period 7 . 

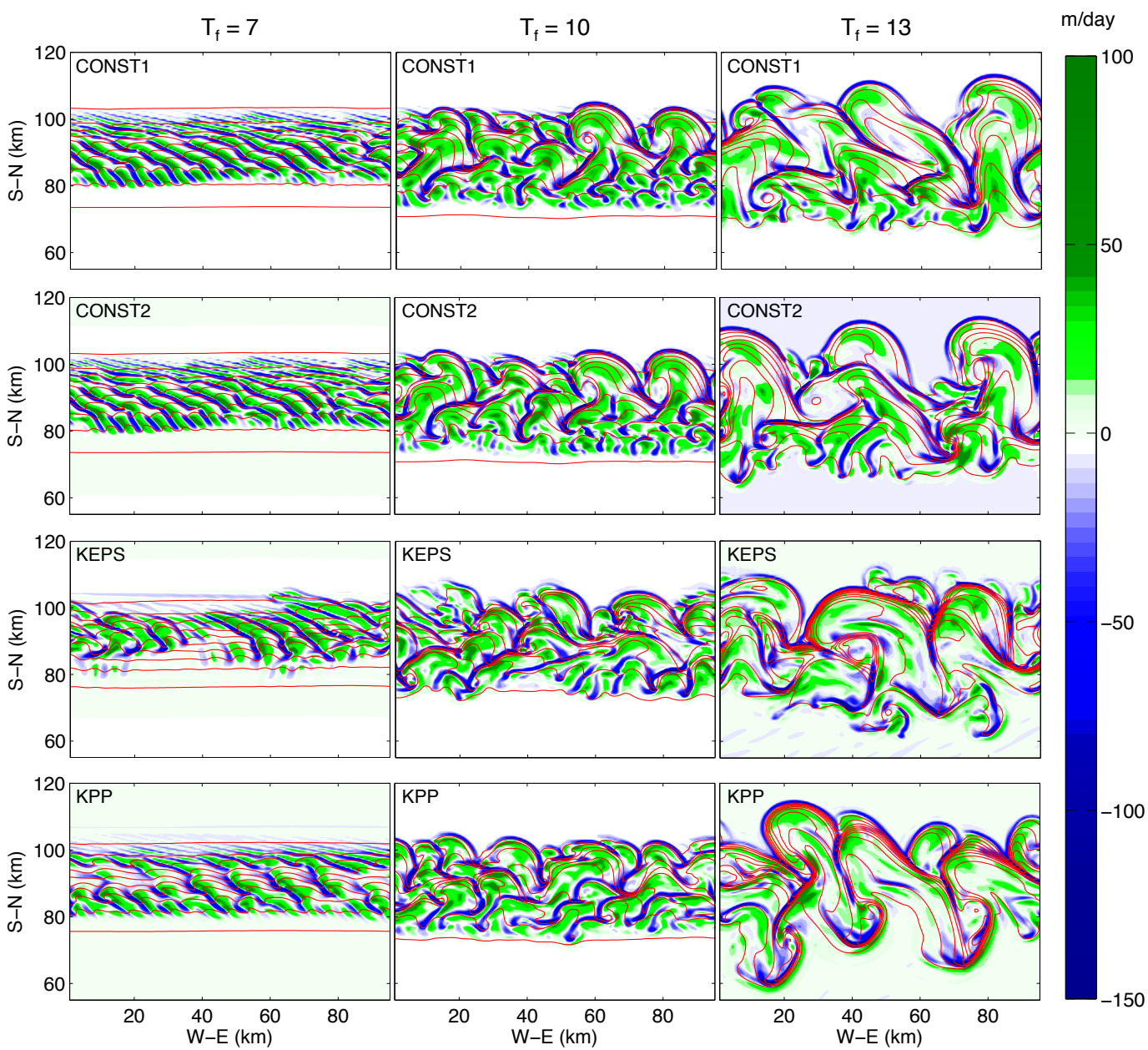

Figure 3: Evolution of vertical velocity $(\mathrm{m} /$ day) at a depth of $10 \mathrm{~m}$, shown as snapshots with isopycnal lines (red) at inertial periods 7, 10 and 13. From the top to the bottom panels, the results are from the simulations CONST1, CONST2, KEPS and KPP respectively. 

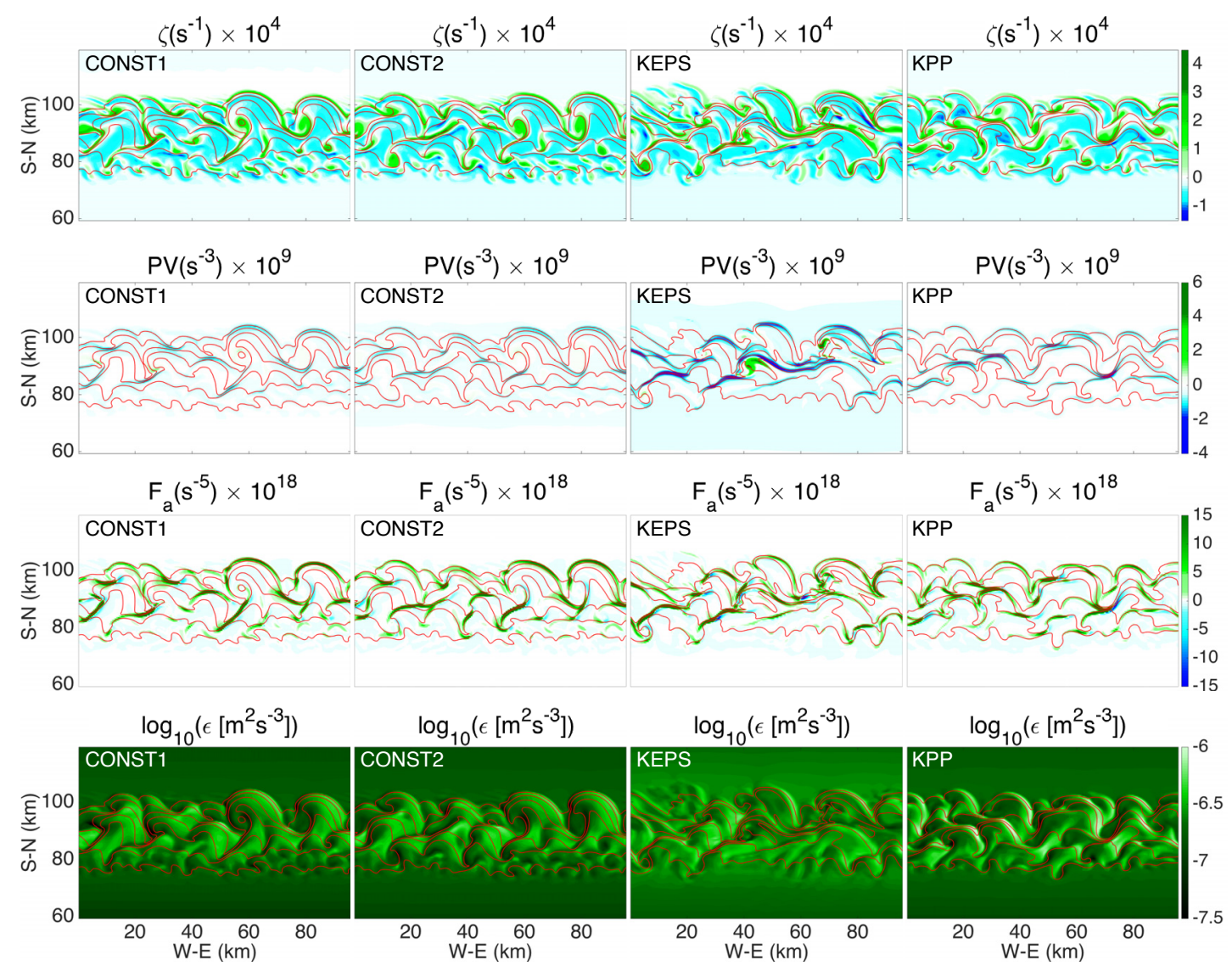

Figure 4: Snapshots at $10 \mathrm{~m}$ depth showing the flow properties (top to bottom) $\zeta$, Ertel $\mathrm{PV}$, frontogenesis by the strain rate $\left(F_{a}\right)$ and $\epsilon$ from the simulations CONST1, CONST2, KEPS and KPP at inertial period 13. 

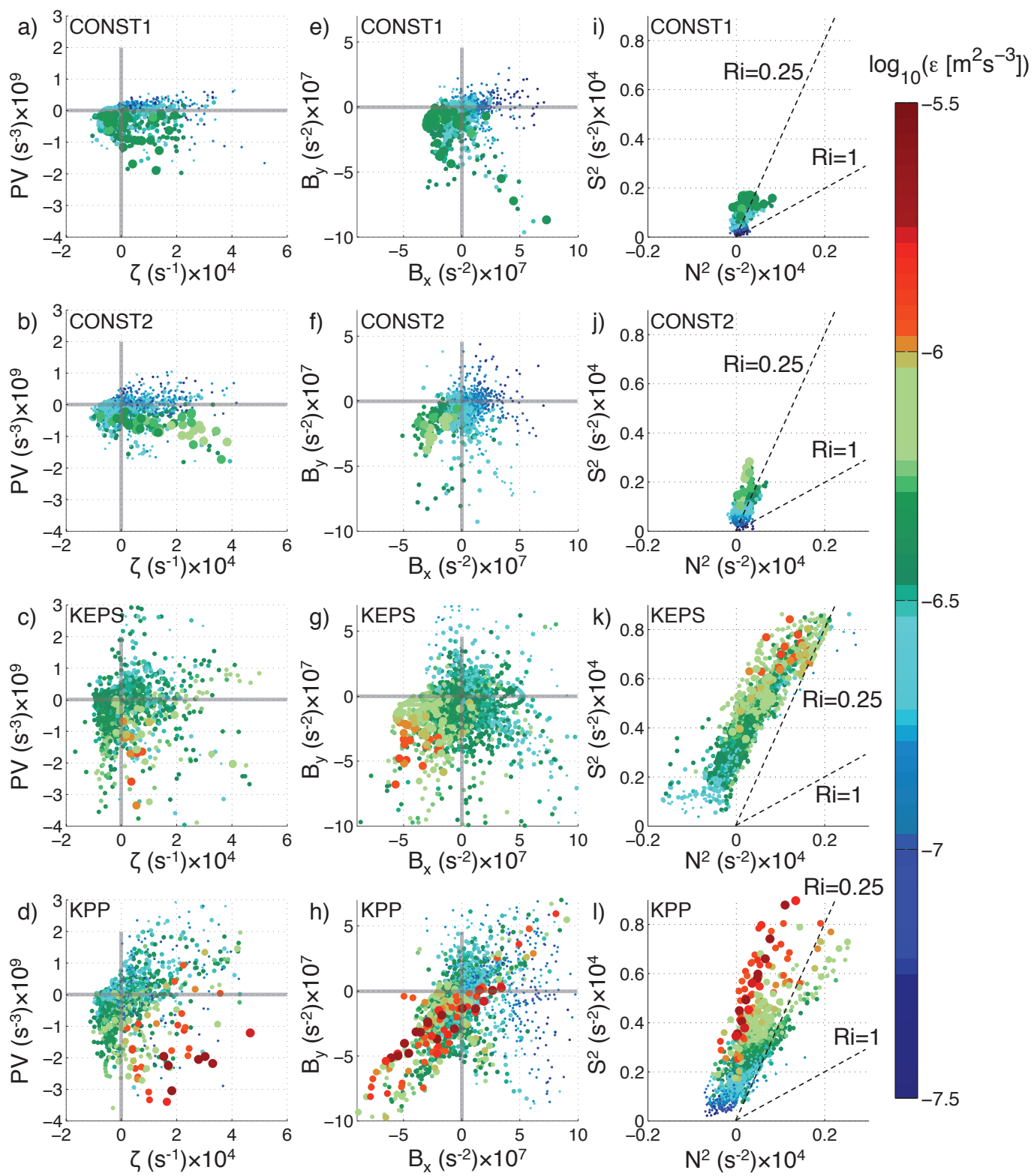

$-6.5$

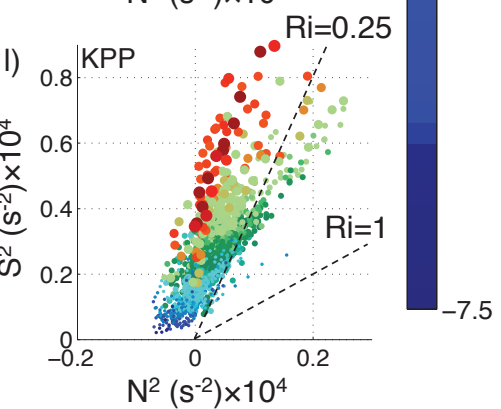

Figure 5: Scatter plots at $10 \mathrm{~m}$ depth over the eddying region at inertial period 10, color coded with $\log _{10}(\epsilon)$. From top to bottom, the rows show the results from CONST1, CONST2, KEPS and KPP. The left column shows scatter plots of $\zeta$ and PV. The middle column shows scatter plots of $B_{x}$ and $B_{y}$. The right column shows scatter plots of $N^{2}$ and $S^{2}$. The variables on the $x$ and $y$ axes are normalized to $\mathrm{O}(1)$ values by multiplying with integral powers of 10 . The regions with enhanced dissipation are shown in larger markers compared to the other regions so that they can be distinctly spotted. 

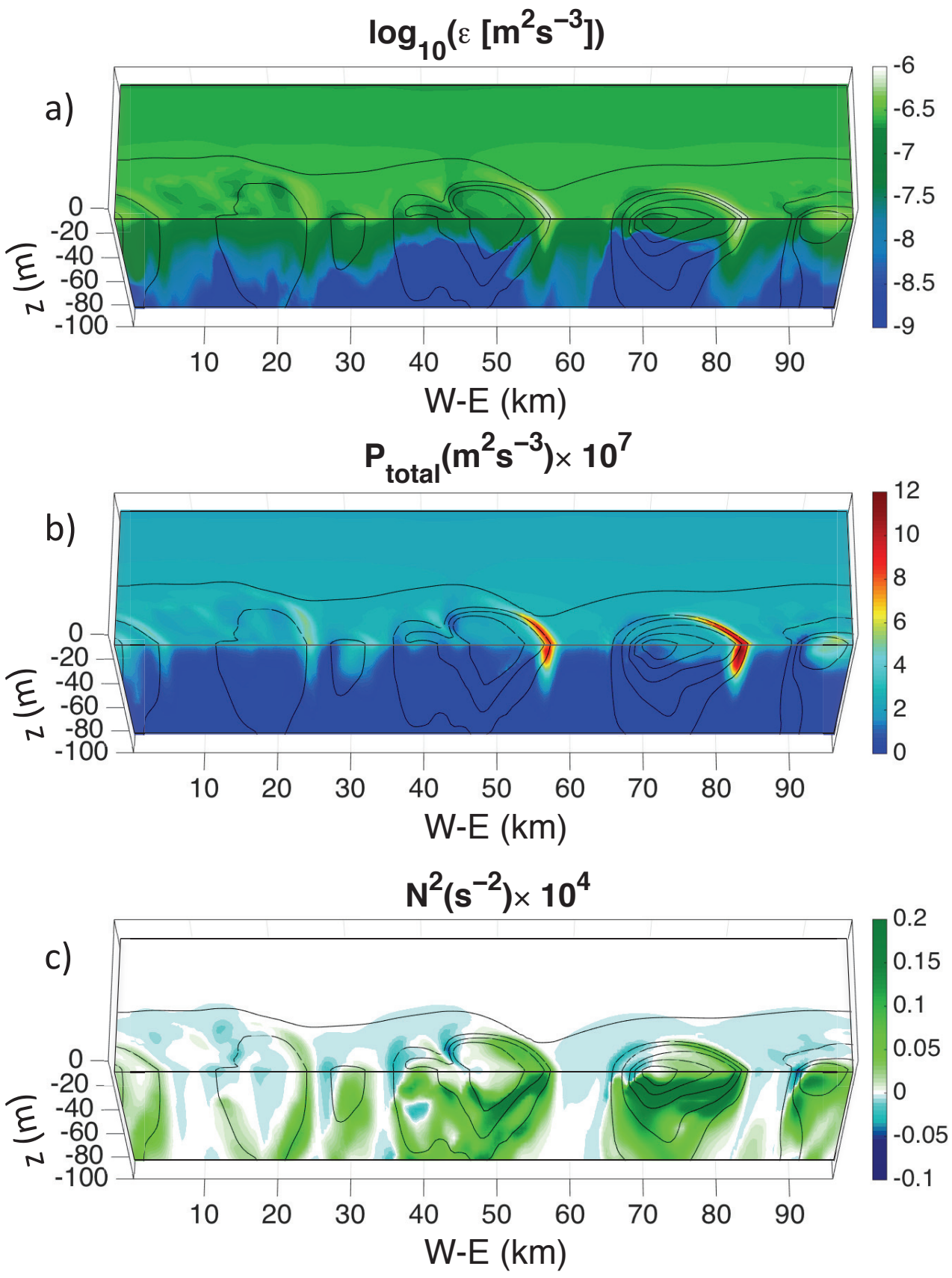

Figure 6: 3D contours from the KEPS simulation at inertial period 10, showing the zonal transect at $y=100 \mathrm{~km}$ and the plan view at a depth of $10 \mathrm{~m}$ for the properties: a) $\log _{10}(\epsilon)$, b) $P_{\text {total }}$, and c) $N^{2} . P_{\text {total }}$ and $N^{2}$ are normalized to $\mathrm{O}(1)$ values by multiplying with $10^{7}$ and $10^{4}$ respectively. 

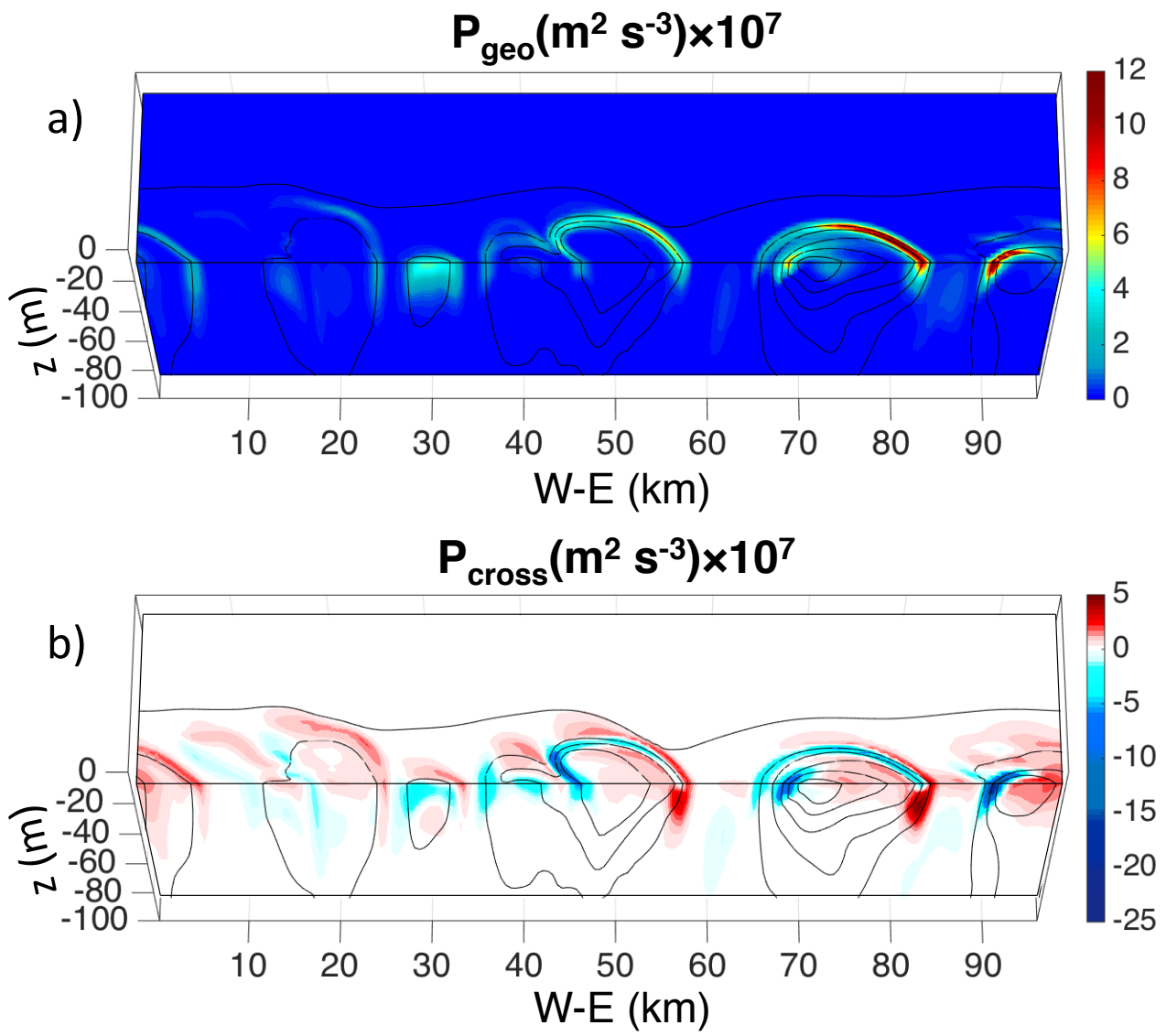

Figure 7: 3D contours from the KEPS simulation at inertial period 10, showing the zonal transect at $y=100 \mathrm{~km}$ and the plan view at a depth of $10 \mathrm{~m}$ for the following properties: a) $P_{\text {geo }}$, and b) $P_{\text {cross }}$. The variables are normalized to $\mathrm{O}(1)$ values by multiplying with $10^{7}$. 

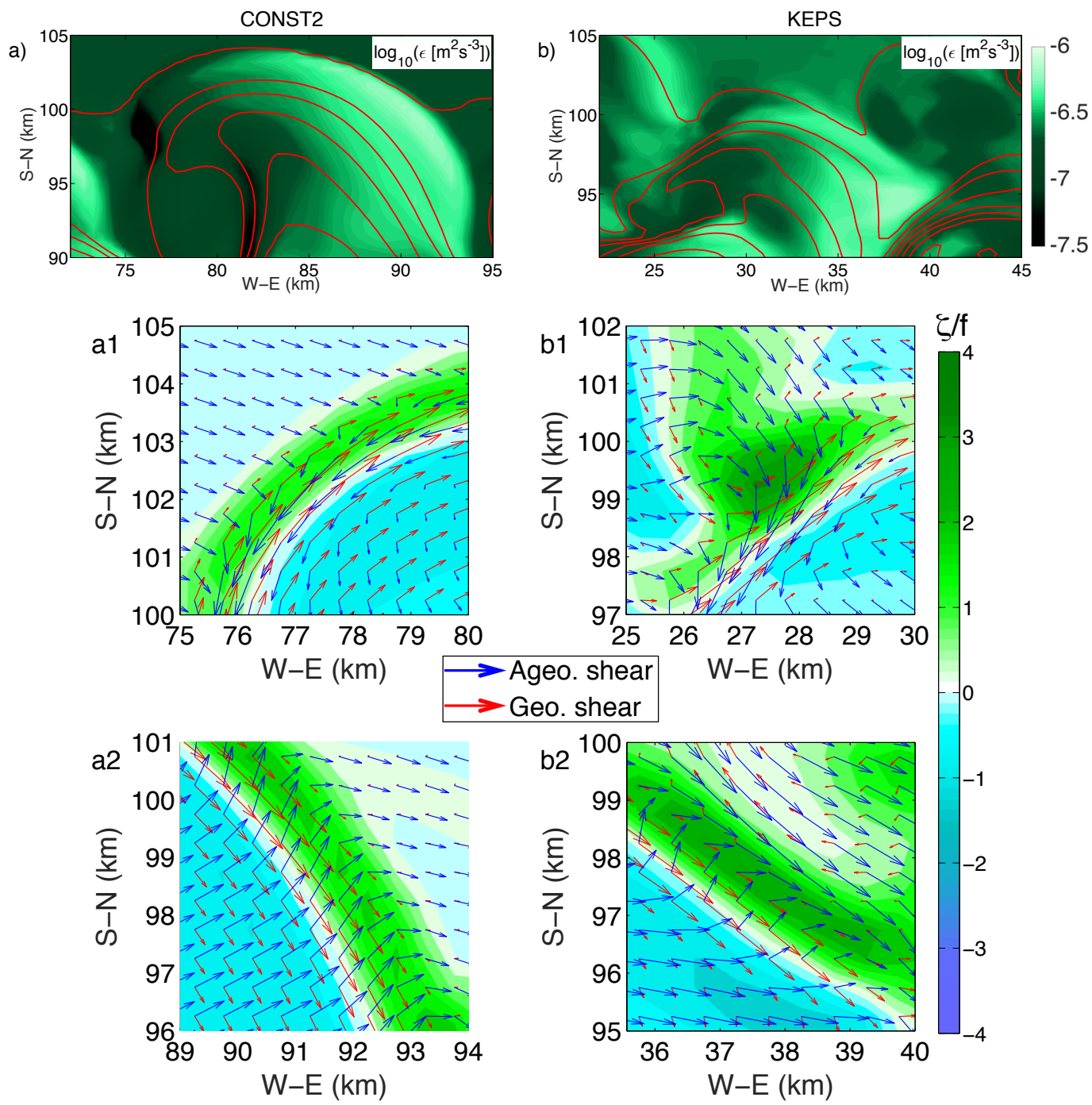

Figure 8: Plots a) and b) show an $\mathrm{O}(10 \mathrm{~km})$ eddy from the simulations CONST2 and KEPS respectively, with contours of $\log _{10}(\epsilon)$ and isopycnals (red line) at $10 \mathrm{~m}$ depth and inertial period 10. a1) and a2) show the directions of the shear components on the destratifying and restratifying edges of the eddy in the CONST2 simulation respectively. Similarly, b1) and b2) show the shear components on the destratifying and restratifying edges on the eddy from the KEPS simulation respectively. Plots a1, a2, b1 and b2 are color-coded with $\zeta / f$. 

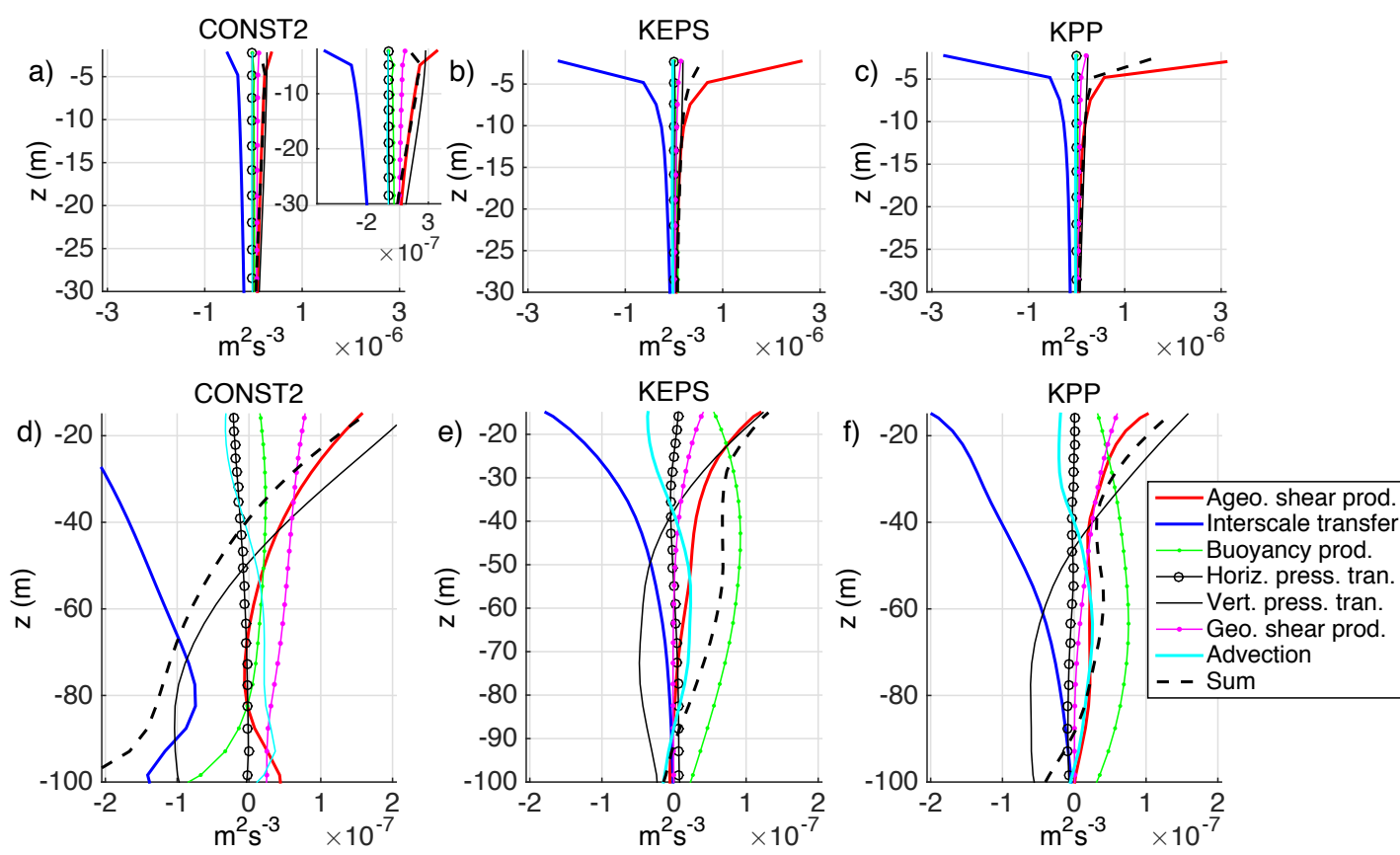

Figure 9: Resolved EKE budgets for the simulations CONST2, KEPS and KPP at inertial period 13, averaged over the eddying region. The top panel shows the budget within the top $30 \mathrm{~m}$ of the mixed layer. Since the averaged EKE budget in CONST1 is similar to that in CONST2, we show only the results from CONST2, KEPS and KPP. 

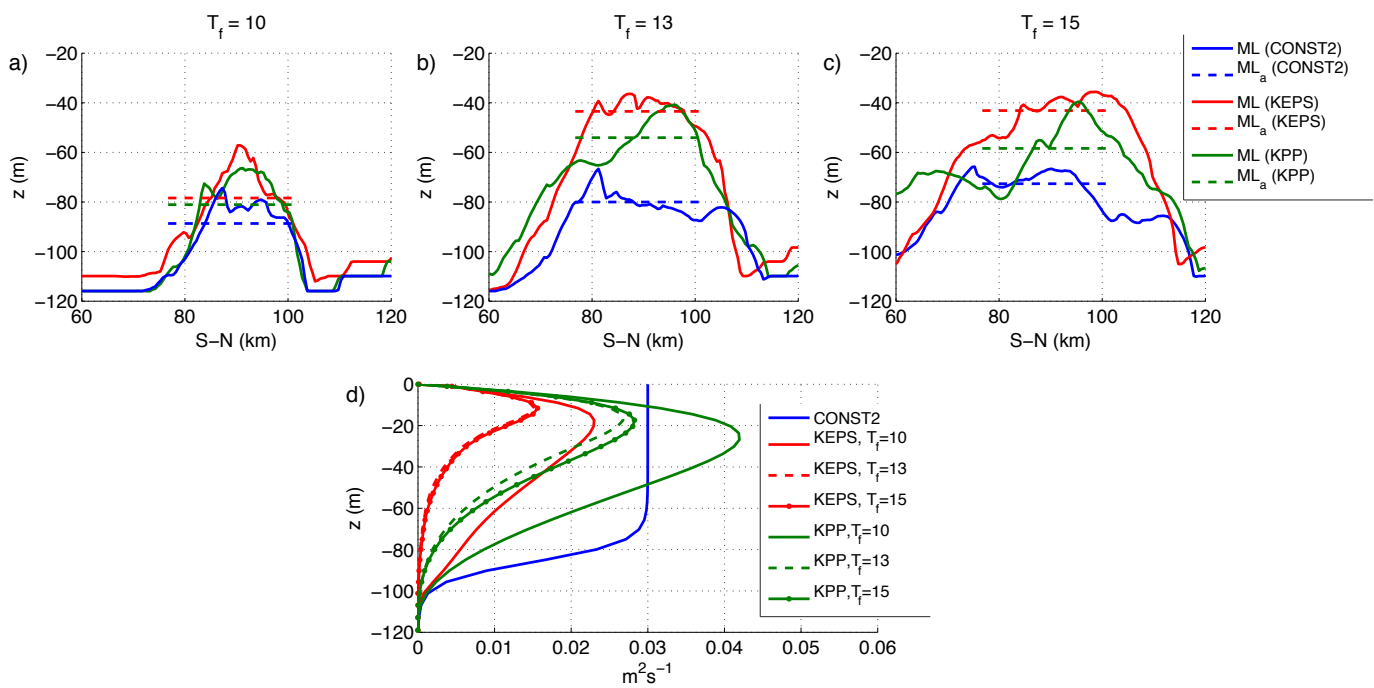

Figure 10: Plots a), b) and c) show the zonally averaged mixed-layer depth (MLD) (solid lines) at inertial periods 10, 13 and 15 from simulations CONST2, KEPS and KPP. The MLD averaged spatially over the eddying region is shown in dashed lines. Plot d) shows the spatially averaged vertical eddy viscosity at inertial periods 10, 13 and 15 from KEPS and KPP alongside the prescribed eddy viscosity in CONST2.
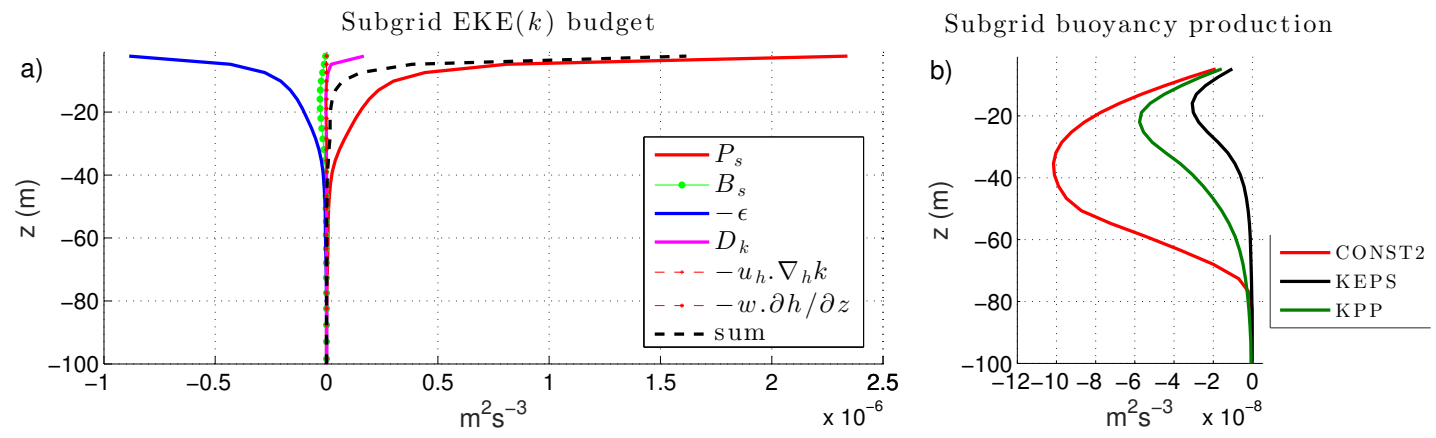

Figure 11: a) Subgrid-scale EKE budget at inertial period 13 from KEPS. b) Subgrid buoyancy production for CONST2, KEPS and KPP, spatially averaged over the eddying region. 